ISSN: $1984-6266$

\title{
Índice de sentimento do investidor no mercado de ações brasileiro
}

Recebimento:

24/01/2020

\author{
Bruna Thaísa Braga Nogueira \\ UFMG - Universidade Federal de Minas Gerais \\ brunatbnogueira@gmail.com \\ Bruna Camargos Avelino \\ UFMG - Universidade Federal de Minas Gerais \\ bcavelino@gmail.com
}

Ana Carolina Vasconcelos Colares

UFMG - Universidade Federal de Minas Gerais carolina_colares@hotmail.com

Daniel Eustáquio Assis dos Reis

UFMG - Universidade Federal de Minas Gerais danieleareis1@gmail.com

\section{Aprovação: \\ 10/01/2021}

\section{Editor responsável pela aprovação do artigo:}

Dra. Nayane Thays Krespi Musial

\section{Editor responsável pela edição do} artigo:

Dra. Luciana Klein

\section{Avaliado pelo sistema: Double Blind Review}

\section{Resumo}

Na teoria clássica de finanças, assume-se que os efeitos das decisões de agentes não racionais são rapidamente eliminados pela atividade de agentes racionais, impedindo a persistência de desvios injustificados nos preços das ações. Nessa abordagem, o sentimento do investidor não é considerado um fator relevante. Em contrapartida, as finanças comportamentais sugerem que a influência de vieses cognitivos sobre os agentes gera padrões significativos no mercado e não explicados pelos fundamentos. Desse modo, o principal objetivo deste trabalho foi construir um índice de sentimento do investidor para o mercado brasileiro, no período de 2008 a 2017. A amostra foi composta por 150 empresas não-financeiras com ações negociadas na B3 e que atenderam a um critério mínimo de liquidez em bolsa. A técnica estatística utilizada foi a Análise de Componentes Principais, selecionando-se cinco proxies já empregadas em estudos anteriores: turnover das ações, quantidade de IPOs, percentual de ações nas novas emissões, prêmio de dividendos e proporção de baixas e altas. A evolução do índice de sentimento construído mostrou-se condizente com os momentos econômicos no país, embora as variáveis turnover e proporção de baixas e altas tenham apresentado sinal diferente do esperado. Posteriormente, realizou-se uma análise de correlação entre 0 índice de sentimento e o lbovespa. Constatou-se uma correlação positiva e estatisticamente significativa entre as duas variáveis, indicando que altos (baixos) níveis de sentimento são parcialmente acompanhados de tendências de subida (queda) no lbovespa.

Palavras-chave: Finanças Comportamentais. Índice de Sentimento do Investidor. Análise de Componentes Principais.

A reprodução dos artigos, total ou parcial, pode ser feita desde que citada a fonte.

PROGRAMA DE PÓS-GRADUAÇÃO EM CONTABILIDADE UFrR MESTRADO E DOUTORADO

DOI:

http://dx.doi.org/10.5380/rcc.v12i3.71338 


\title{
Bruna Thaísa Braga Nogueira, Bruna Camargos Avelino, Ana Carolina Vasconcelos Colares \& Daniel \\ Eustáquio Assis dos Reis.
}

\section{INVESTOR SENTIMENT INDEX IN THE BRAZILIAN STOCK MARKET}

\begin{abstract}
Classical finance theory assumes that the effects of non-rational agents' decisions are quickly eliminated by rational agents' activity, preventing the persistence of unjustified deviations in the stock prices. In this approach, investor sentiment is considered an irrelevant factor. Contrariwise, behavioral finance suggests that the influence of cognitive biases on agents causes significant patterns in the market, which are not explained by fundamentals. Therefore, this work aims to build an investor sentiment index to the Brazilian market, for the period of 2008 to 2017. The sample consisted of 150 non-financial companies listed at B3, considering a liquidity restriction. The index was estimated by principal components analysis, selecting five proxies already employed in previous studies: share turnover, number of IPOs, equity share in new issues, dividend premium and trading index. Results showed consistency among the evolution of the sentiment index and Brazilian economic cycles, although turnover and trading index have not presented the expected sign. Correlation analysis between investor sentiment index and lbovespa was also made. Empirical findings indicated a positive and statistically significant correlation, denoting that high (low) levels of investor sentiment are partially accompanied by a rising (falling) trend in lbovespa.
\end{abstract}

Keywords: Behavioral Finance. Investor Sentiment Index. Principal Component Analysis.

\section{Introdução}

A teoria clássica de finanças apresenta como um de seus pilares a hipótese dos mercados eficientes (HME), preconizada por Fama $(1965,1970)$. De acordo com a HME, os preços refletem todas as informações disponíveis acerca do valor intrínseco de um ativo. Eventuais divergências são corrigidas pela atuação de investidores sofisticados, indivíduos com habilidade para estimar os efeitos das informações sobre os valores reais das ações (Fama, 1965). Além disso, não é possível vencer o mercado - isto é, obter retornos consistentemente superiores aos retornos do mercado como um todo -, a menos que se incorra em um risco sistemático maior (Shleifer, 2000).

A racionalidade dos agentes econômicos é uma premissa fundamental da teoria clássica. Nessa abordagem, os investidores atualizam adequadamente suas crenças e expectativas ao receber novas informações, não se sujeitando a vieses emocionais (Statman, 1995; Thaler, 2016). Tais vieses são definidos como erros sistemáticos de julgamento, causados por atalhos mentais, suposições e intuições envolvidas na tomada de decisão (Kahneman \& Tversky, 1974). O paradigma clássico argumenta que, ainda que alguns agentes não sejam racionais, em mercados altamente competitivos os efeitos de suas decisões são eliminados pela atividade dos agentes racionais (Barberis \& Thaler, 2003).

Nas últimas décadas, entretanto, diversos estudos documentaram a dificuldade dos modelos clássicos em explicar fenômenos financeiros observados no mercado, como episódios especulativos e bolhas (De Long, Shleifer, Summers \& Waldmann, 1990; Hirshleifer \& Shumway, 2003; Stambaugh, Yu \& Yuan, 2012; De Bondt \& Thaler, 1985). Por isso, os fundamentos e a validade da teoria tradicional têm sido questionados pela abordagem comportamental (Baker \& Wurgler, 2007; Schaul, 2013; Yoshinaga, 2009; Zhang, 2008).

Conforme De Bondt, Muradoglu, Shefrin e Staikouras (2008), as finanças comportamentais são o estudo de como a psicologia influencia decisões financeiras em famílias, mercados e organizações. Thaler (2016) argumenta que, ao incorporar ideias perspicazes de outras ciências sociais, o ramo oferece uma oportunidade para desenvolver melhores modelos de comportamento econômico, incrementando-os com dados reais em vez de axiomas. 
Um dos pilares da abordagem comportamental é o pressuposto de que os agentes estão sujeitos a vieses cognitivos que influenciam sua percepção acerca dos riscos e dos fluxos de caixa futuros (Baker \& Wurgler, 2007). Além disso, pressupõe-se que quando um ativo está indevidamente precificado, estratégias para corrigir a precificação podem ser arriscadas e custosas, logo, não atrativas para os investidores racionais (Barberis \& Thaler, 2003). Diante de tais premissas, ao superestimar retornos esperados em determinados períodos e subestimá-los em outros períodos, investidores podem gerar uma distribuição não aleatória dos preços (Zhang, 2008).

Para Shefrin (2009), um dos problemas centrais da teoria de precificação de ativos é entender como os mercados agregam as crenças e as preferências dos investidores. Entretanto, o desvio sistemático dos preços em relação aos seus valores intrínsecos é uma questão controversa, devido às dificuldades empíricas de mensuração (Brown \& Cliff, 2005). Problemas similares emergem em relação ao sentimento do investidor, dada a necessidade de se determinar previamente o que a medida ideal deveria capturar (Zhang, 2008).

Dentre as definições de sentimento apresentadas na literatura, pode-se citar a propensão do investidor a especular, o otimismo ou o pessimismo em relação às ações de forma geral e o reflexo das expectativas dos investidores (Baker \& Wurgler, 2006; Hilliard, Narayanasamy \& Zhang, 2016). Neste trabalho, o sentimento é definido como tudo aquilo que "leva a desvios de preços não explicados pela variação dos fundamentos das empresas" (Yoshinaga, 2009, p. 122).

Kim e Ha (2010) classificam as medidas de sentimento em três categorias: diretas, indiretas e híbridas. 0 primeiro grupo baseia-se em questionários que avaliam diretamente o sentimento dos participantes. 0 segundo grupo é composto por dados oriundos do próprio mercado (proxies financeiras). Já as medidas híbridas agrupam medidas diretas e indiretas. Schaul (2013) e Fernandes (2015) acrescentam, ainda, medidas alternativas advindas do conteúdo textual e informacional de jornais, redes sociais, sites de busca e boletins de investimento. Destaca-se, entretanto, que não há um índice definitivo e amplamente consolidado na literatura, dado que até mesmo as definições de sentimento podem variar conforme 0 autor (Bank \& Brustbauer, 2014). Apesar disso, a literatura recente já apresenta um consenso de que o sentimento do investidor afeta os preços das ações (Schaul, 2013). Dessa forma, a questão principal refere-se a mensurá-lo e quantificar seus efeitos.

Brown e Cliff (2005) afirmam que o excessivo otimismo (pessimismo) em determinado período leva à sobrevalorização (subvalorização) das ações. Os autores concluem que tal otimismo (pessimismo) tende a ser seguido, no longo prazo, por um período de queda (alta), à medida que o mercado reverte os preços aos seus valores intrínsecos. Resultados semelhantes foram encontrados por Schmeling (2009), que documentou também uma maior influência do sentimento em países propensos ao comportamento de massa e à sobrerreação.

Embora o número de trabalhos empíricos acerca do sentimento do investidor tenha aumentado significativamente nos últimos anos, os resultados não são uniformes. Alguns autores concluíram, por exemplo, que parte do poder de previsão do sentimento pode ser atribuído a fundamentos e a variáveis macroeconômicas, como os ciclos da economia ou o nível de expansão ou recessão, e não a traços puramente comportamentais (Chung \& Hung; Yeh, 2012; Sibley, Xing \& Zhang, 2012)

Diante do que foi tratado, este estudo busca responder ao seguinte problema de pesquisa: de que forma é possível mensurar o sentimento do investidor no mercado de ações brasileiro? 0 objetivo deste trabalho é, portanto, utilizar variáveis do mercado de ações para construir um índice de sentimento do investidor no Brasil, para o período de 2008 a 2017.

A definição de uma medida adequada de sentimento visa auxiliar tanto investidores quanto reguladores (Martins, Pereira, Amorim, Oliveira \& Oliveira, 2010). O primeiro grupo pode identificar o sentimento do mercado em determinado momento e evitar erros de precificação, enquanto o segundo grupo tem a oportunidade de se adiantar a um potencial choque de mercado e implementar ajustes preventivos.

Baker e Wurgler (2006) propuseram a criação de um índice de sentimento utilizando seis proxies advindas do mercado financeiro. Desde então, o uso dessa ferramenta aumentou consideravelmente, com 0 


\section{Bruna Thaísa Braga Nogueira, Bruna Camargos Avelino, Ana Carolina Vasconcelos Colares \& Daniel Eustáquio Assis dos Reis.}

objetivo principal de verificar se o sentimento é capaz de prever as taxas de retorno das ações (Sibley, Xing \& Zhang, 2012). Entretanto, a maioria dos estudos é focada em mercados de maior dimensão, com destaque para o norte-americano.

Esse estudo justifica-se pela importância crescente da área de finanças comportamentais e pela necessidade de explorar um tópico ainda em construção. Como contribuição teórica, dada a escassez de pesquisas voltadas para o sentimento do investidor no mercado brasileiro, espera-se contribuir com a literatura existente. Como contribuição prática, o trabalho busca melhorar a compreensão dos padrões de negociação observados no Brasil, fornecendo ferramentas para que os agentes do mercado identifiquem as tendências, as expectativas e os possíveis desvios na precificação das ações.

\section{Referencial Teórico}

\subsection{Finanças Clássicas}

De acordo com Merton (1992), até a década de 1950, as finanças eram uma disciplina majoritariamente descritiva, focada em questões legais e institucionais. A evolução subsequente, porém, deu origem a uma rigorosa teoria econômica, sujeita a verificações e testes empíricos. Dentre as principais contribuições às finanças modernas (ou clássicas), tem-se a seleção de carteiras de Markowitz (1952), o Capital Asset Pricing Model (CAPM) de Sharpe (1964), Lintner (1965) e Mossin (1966) e a hipótese dos mercados eficientes (HME) formalizada por Fama $(1965,1970)$.

Em relação ao primeiro aspecto apontado, Markowitz (1952) forneceu uma relevante contribuição à teoria de apreçamento de ativos por meio da Teoria de Carteiras. O autor preconiza a utilização de dois parâmetros para a formação de carteiras: a média e a variância dos retornos. Ademais, o risco do ativo individual deve ser analisado sob a ótica da sua covariância com todo o portfólio, de modo a evitar a alocação de ativos com alta covariância entre si.

Posteriormente, em um estudo não publicado, Treynor (1961) desenvolveu um modelo que incorpora o risco ao preço do ativo. De modo similar, porém independente, Sharpe (1964) concluiu que o risco não diversificável - isto é, o risco não passível de eliminação por meio de uma alocação eficiente de recursos - é diretamente relacionado ao retorno esperado do ativo. Seu trabalho, aperfeiçoado por Lintner (1965) e Mossin (1966), deu origem ao CAPM, o modelo de apreçamento mais debatido na literatura.

O CAPM determina que o retorno esperado de qualquer ativo é uma função linear de três variáveis: a taxa de retorno do ativo livre de risco, o retorno esperado da carteira de mercado e o beta, medida de risco sistêmico que expressa a sensibilidade do ativo em relação à carteira de mercado. Desse modo, investidores recebem um prêmio de risco, proporcional ao beta, como recompensa por manterem um ativo de risco no portfólio. Dentre as premissas assumidas pelo CAPM, tem-se a homogeneidade das expectativas dos investidores, a preferência por ativos de maior retorno e de menor risco e a existência de uma taxa livre de risco na qual os indivíduos podem investir e tomar empréstimos (Lintner, 1965).

Nas últimas décadas, a validade do CAPM tem sido questionada em duas frentes: além não se alinharem ao modelo em alguns testes, os retornos têm estado relacionados a outros fatores além do beta (Brealey, Myers \& Allen, 2013). Para Fama e French (2004), os problemas empíricos podem refletir falhas teóricas advindas das premissas simplificadoras. Os autores apontam, por exemplo, que a abrangência da carteira de mercado teórica dificulta a obtenção de uma proxy adequada.

Diante das incongruências observadas, estudos posteriores utilizaram diferentes metodologias para precificar os ativos, alterando a técnica estatística ou os fatores explicativos dos retornos. Merton (1973), por exemplo, desenvolveu o CAPM intertemporal (ICAPM), no qual o tempo é tratado como uma variável contínua. 
Ross (1976) apresentou o Arbitrage Pricing Theory (APT), um modelo multifatorial que busca explicar os preços por meio de fatores, podendo ser características relacionadas à empresa ou variáveis macroeconômicas.

Fama e French (1993) desenvolveram o modelo de três fatores, sendo estes o prêmio de risco, o fator tamanho e o fator book-to-market. O efeito tamanho, descrito por Banz (1981), representa a tendência de que os retornos das ações de empresas pequenas sejam superiores àqueles apresentados por empresas grandes. Já o índice book-to-market (razão entre o valor contábil e o valor de mercado) é utilizado para demonstrar 0 efeito valor: empresas com alto índice book-to-market tendem a apresentar retornos mais altos (Fama \& French, 1992; Rosenberg, Reid \& Lanstein, 1985).

Vários outros padrões de retornos são contemplados pela literatura. Jegadeesh e Titman (1993) documentaram o efeito momento, isto é, ações com baixos retornos no último ano tendem a apresentar baixos retornos nos meses seguintes, enquanto ações com altos retornos passados tendem a apresentar altos retornos subsequentes. Carhart (1997) adicionou o momento ao modelo de três fatores de Fama e French (1993), propondo o modelo de quatro fatores. Posteriormente, Fama e French (2015) adicionaram duas variáveis ao seu modelo anterior, lucratividade e investimento, criando o modelo de cinco fatores.

Os padrões regulares no comportamento dos retornos, não justificados pela eficiência de mercado, são chamados de anomalias (Camargos \& Barbosa, 2003). Pesquisadores têm debatido se esses padrões constituem erros de especificação dos modelos ou prêmios pelo risco. Proponentes das finanças clássicas buscam explicações racionais baseadas na compensação pelo risco, pois, desde que se incorra em um risco maior, retornos anormais não são inconsistentes com a HME. Economistas comportamentais, por sua vez, passaram a ter dois objetivos: encontrar anomalias e desenvolver uma teoria que as explicasse (Thaler, 2015).

No que tange à hipótese dos mercados eficientes (HME), um mercado é considerado eficiente quando os preços refletem de modo integral as informações disponíveis (Fama, 1970). Essa foi a proposta central na área de finanças por quase trinta anos, atingindo seu auge na década de 1970, quando as premissas de expectativas racionais foram endossadas pela maior parte do círculo acadêmico (Shiller, 2003; Shleifer, 2000). De acordo com Read (2012), a HME provocou mais debates do que qualquer outro conceito na história de finanças.

A eficiência de mercado está associada à ideia de random walk, isto é, a independência dos preços atuais em relação aos preços anteriores (Malkiel, 2003). Uma vez que as notícias são imprevisíveis e as mudanças nos preços são provocadas pelo fluxo de novas informações, os preços também seguirão um caminho imprevisível e aleatório, impossibilitando a obtenção de retornos consistentemente superiores aos retornos de mercado. Fama (1965) afirma que, embora as séries temporais provavelmente não apresentem perfeita independência, a premissa pode continuar sendo considerada, contanto que a dependência observada não seja suficiente para permitir previsões futuras de preços e ganhos anormais.

A HME assume que se houvesse padrões sistemáticos nos preços, investidores racionais explorariam rapidamente a oportunidade e conduziriam os preços de volta ao valor intrínseco do ativo, eliminando as disparidades. Esse mecanismo de correção de distorções é chamado de arbitragem, no qual a compra de um ativo simultânea à venda de outro caracteriza uma operação sem risco e com garantia de retorno positivo (Barberis \& Thaler, 2003; Yoshinaga, 2009). Em um mercado eficiente, não há oportunidades prolongadas de arbitragem, visto que o surgimento de anomalias levaria a modelos de previsão autodestrutivos (Timmermann \& Granger, 2004).

Embora se reconheça a dificuldade de mensurar o valor intrínseco de uma ação, o preço é tido como a melhor estimativa (Fama, 1965). Discrepâncias em relação ao valor real da ação, não justificadas pelas informações ou fundamentos, são chamadas de noise (Black, 1986). Os desvios nos preços provocados por noise traders não são inconsistentes com a eficiência de mercado, pois, desde que sejam aleatórios, em média eles serão cancelados mutuamente.

Fama (1970) divide os testes empíricos de eficiência em três categorias: forma fraca, forma semiforte e forma forte. Na forma fraca, as informações refletidas pelos preços atuais referem-se apenas aos preços 


\section{Bruna Thaísa Braga Nogueira, Bruna Camargos Avelino, Ana Carolina Vasconcelos Colares \& Daniel Eustáquio Assis dos Reis.}

passados. Ao expandir esse conjunto para todas as informações publicamente disponíveis, tem-se a forma semiforte. Por fim, a forma forte inclui todas as informações, públicas e privadas. $\mathrm{O}$ autor, porém, admite que a forma forte de eficiência dificilmente represente uma descrição adequada da realidade, sendo mais bem utilizada apenas como benchmark. Assim, a maior parte dos estudos sobre a previsibilidade do mercado testa a HME em sua forma fraca ou semiforte.

\subsection{Finanças Comportamentais}

A partir da década de 1980, intensificaram-se os questionamentos de diversos autores acerca dos pressupostos das finanças clássicas. Shiller (1981), por exemplo, apontou que os movimentos dos preços das ações são maiores do que as variações nos dividendos esperados, sugerindo que a volatilidade dos preços não pode ser justificada apenas por novas informações. Embora questionado por autores como Malkiel (2003) e Rubinstein (2001), o estudo motivou investigações posteriores sobre a questão, conhecida na literatura como volatility puzzle (Campbell, 1999).

De Bondt e Thaler (1985) documentaram a reversão dos retornos no longo prazo. Os autores ordenaram as ações conforme 0 seu desempenho nos últimos três anos, formando carteiras de ações com baixo desempenho (perdedoras) e alto desempenho (vencedoras). Após um horizonte de três a cinco anos, as ações perdedoras apresentaram retornos superiores ao retorno de mercado, ao passo que as ações vencedoras apresentaram retornos inferiores. As reversões são atribuídas às reações excessivas dos investidores a algumas notícias, que desviam os preços dos seus valores fundamentais e, posteriormente, corrigem as avaliações.

Lee, Shleifer e Thaler (1991) analisaram o caso dos closed-end funds, fundos de investimento fechados cujas cotas são negociadas em bolsa e que aplicam seu patrimônio em ativos também listados. Para liquidar sua posição, o investidor deve vender suas cotas a outros investidores. Os autores, então, discutiram 0 problema conhecido como closed-end fund puzzle: as cotas dos fundos geralmente são negociadas a preços diferentes dos valores líquidos dos ativos (Net Asset Value - NAV) que os compõem, apresentando um desconto em relação ao NAV. Para os autores, as explicações tradicionais (custos de agência, despesas com impostos e taxas e iliquidez dos ativos) não são suficientes para justificar as diferenças de preços. Sugere-se, assim, que o sentimento do investidor teria influência sobre a questão.

Os fenômenos que contradiziam os fundamentos econômicos motivaram o interesse pela economia comportamental (Loewenstein, 1992). A fim de compreender melhor os eventos, surgiu a necessidade de se relaxar a premissa de racionalidade, isto é, a ideia de que os agentes atualizam adequadamente suas crenças e de que suas decisões são compatíveis com a maximização da utilidade esperada (Barberis \& Thaler, 2003). Nesse contexto, as crenças e preferências dos indivíduos passaram a ser tidas como possíveis causas de violações dos axiomas das finanças clássicas.

Os pilares das finanças comportamentais são os limites à arbitragem e a psicologia (Shleifer \& Summers, 1990). Conforme Assaf Neto (2014, p. 150), "a arbitragem geralmente ocorre em mercados que apresentam discrepâncias entre os preços praticados: os preços são diferentes quando deveriam ser iguais". Para a teoria clássica de finanças, os investidores racionais explorarão rapidamente as oportunidades de arbitragem, trazendo os preços de volta ao seu valor fundamental (Fama, 1965). Os arbitradores adquirem um ativo no mercado no qual o preço está mais baixo (forçando o preço para cima), e o vendem no mercado em que está mais valorizado (forçando o preço para baixo).

A abordagem comportamental presume a existência de limites à arbitragem, pois as operações práticas são consideravelmente mais complexas do que a teoria sugere (Shleifer \& Vishny, 1997). Argumenta-se que alguns riscos são capazes de inibir a correção da precificação pelos investidores racionais, como 0 risco 
fundamental e o risco advindo da imprevisibilidade das ações dos investidores irracionais (Ackert \& Deaves, 2010).

De acordo com Barberis e Thaler (2003), o risco fundamental refere-se ao risco atrelado ao ativo sendo negociado, como uma notícia negativa sobre uma ação adquirida. Cientes desse risco, os arbitradores normalmente realizam uma venda a descoberto (short sell) de um ativo similar que, teoricamente, apresenta um comportamento de preços semelhante ao primeiro. Entretanto, dois ativos raramente são substitutos perfeitos, impossibilitando a eliminação de todo o risco fundamental.

Já o risco proveniente dos movimentos dos investidores irracionais refere-se à possibilidade de que as distorções nos preços não sejam revertidas - ou até se tornem mais extremas - no curto prazo. Nesse caso, se 0 arbitrador liquidar sua posição antes que o preço se recupere, poderá incorrer em perdas significativas. De acordo com De Long et al. (1990), qualquer arbitrador com um horizonte curto e limitado de tempo incorrerá nesse tipo de risco, conhecido como noise trader risk.

Custos de transação, como comissões, spreads e restrições à venda a descoberto, também podem limitar a arbitragem (Barberis \& Thaler, 2003). Castro (2015) verificou que, no mercado brasileiro, as taxas cobradas pelo aluguel de ações estão positivamente relacionadas à ineficiência de mercado: quanto maiores as taxas, maiores os desvios dos preços em relação aos seus valores fundamentais.

O segundo pilar das finanças comportamentais é a psicologia, que aborda o processo de tomada de decisão e os vieses aos quais os indivíduos estão sujeitos.

Keynes (1936), em seu livro The General Theory of Employment, Interest, and Money, já fazia alusão ao sentimento dos agentes econômicos. Segundo o autor, a tomada de decisão muitas vezes não resulta da multiplicação de benefícios quantitativos por suas probabilidades, mas sim dos chamados animal spirits. 0 termo tornou-se uma expressão econômica, referindo-se à forma como os indivíduos lidam com ambiguidade e incerteza (Akerloff \& Shiller, 2009).

O estudo de como o cérebro humano processa informações foi impulsionado a partir da década de 1960, com o desenvolvimento da psicologia cognitiva (Camerer \& Loewenstein, 2004). A partir de então, a análise dos mecanismos que governam o pensamento foi incorporada a outras áreas que também se interessavam pelo comportamento humano, como a economia. Autores como Simon (1955) e Slovic (1972), por exemplo, ressaltaram a necessidade de se aprimorar e tornar mais realistas os modelos econômicos de tomada de decisão, considerando a racionalidade dos indivíduos como limitada.

Nesse contexto, os psicólogos Daniel Kahneman e Amos Tversky forneceram relevantes contribuições, comumente citadas como o marco inicial da área de finanças comportamentais. Em um trabalho publicado em 1974 , os autores investigaram como as heurísticas - estratégias mentais usadas para solucionar problemas de forma rápida, normalmente ignorando parte da informação disponível - podem levar a erros sistemáticos de julgamento. Abordaram três processos cognitivos, especificamente: a representatividade, a disponibilidade e a ancoragem.

O princípio da representatividade refere-se à tendência de se apoiar em estereótipos e de esperar que pequenas amostras sejam representativas da respectiva população. Investidores podem, por exemplo, acreditar que os retornos futuros de uma ação serão particularmente altos devido a uma performance passada favorável ou a informações recentes, causando uma sobrerreação no mercado (Barberis \& Thaler, 2003).

A heurística da disponibilidade diz respeito à formação de julgamentos com base em informações prontamente acessíveis, isto é, informações disponíveis na memória ou correspondentes a um cenário facilmente imaginável. Kahneman e Tversky (1974) ressaltam que, de fato, eventos mais frequentes e prováveis geralmente são lembrados com maior facilidade.

A ancoragem é observada quando as pessoas partem de um valor inicial (âncora) e o ajustam para formar determinada estimativa. $O$ viés de ancoragem refere-se à tendência de que os ajustes não sejam suficientes, ou seja, de que as pessoas se apoiem excessivamente no ponto de referência. Desse modo, suas 


\section{Bruna Thaísa Braga Nogueira, Bruna Camargos Avelino, Ana Carolina Vasconcelos Colares \& Daniel Eustáquio Assis dos Reis.}

estimativas são enviesadas em direção ao valor inicial. Cen, Hilary e Wei (2010) encontraram indícios de que as previsões de lucro feitas por analistas são ancoradas à média de lucro por ação do setor em questão.

Inúmeros outros vieses cognitivos, não necessariamente relacionados a heurísticas, foram abordados pela literatura de finanças comportamentais. Daniel e Hirshleifer (2015) sugerem, por exemplo, que o excesso de confiança dos investidores seja responsável, ao menos em parte, pelo alto volume de transações no mercado. Ao atribuir maior peso às suas próprias opiniões e menor peso às opiniões dos outros agentes, investidores negociam ativa e frequentemente, esperando altos lucros. Porém, os custos de transação não raro tornam seu lucro líquido menor do que aquele dado por uma estratégia passiva.

Além de definir como as crenças dos indivíduos são formadas, fazia-se necessário investigar suas preferências. A observação de violações à teoria da utilidade esperada levou ao surgimento de modelos alternativos de decisão em condições de risco, como a Teoria da Perspectiva ou do Prospecto (Prospect Theory), apresentada por Kahneman e Tversky (1979). Nesse modelo, ganhos e perdas são avaliados em relação a um ponto de referência, que exerce maior influência sobre a decisão do que o valor final da riqueza. Além disso, o ponto de referência pode ser alterado de acordo com a forma de apresentação do problema. $\mathrm{Na}$ Teoria da Perspectiva, a dor associada à perda de determinado valor é maior do que o prazer obtido por um ganho equivalente. Considera-se que os indivíduos são avessos ao risco quando se trata de ganhos, mas optam pelo risco quando se trata de perdas.

Embora a Teoria da Perspectiva seja amplamente aceita como um modelo descritivo de comportamento, ainda há desafios relacionados à sua aplicação em contextos econômicos (Barberis, 2013). De fato, uma das fraquezas da área de finanças comportamentais é a ausência de uma teoria unificada e central (De Bondt et al., 2008). Conforme exposto por Barberis e Thaler (2003), os modelos comportamentais normalmente capturam as crenças dos investidores, suas preferências, ou os limites à arbitragem, mas não os três simultaneamente.

\subsection{Sentimento do Investidor}

Não há, na literatura, uma definição clara e formal de sentimento do investidor. No entanto, de modo geral, o sentimento pode ser definido como o conjunto de crenças errôneas que influenciam a avaliação dos investidores em relação ao valor intrínseco dos ativos (Zhang, 2008). É, portanto, uma expectativa acerca dos fluxos de caixa futuros não justificada pelos fundamentos (Baker \& Wurgler, 2007).

Baker e Wurgler (2006) sugerem que a dificuldade de avaliação das empresas influencia a suscetibilidade dos preços das ações em relação às mudanças no sentimento do mercado. Empresas pequenas, sem histórico de pagamentos de dividendos e com retornos voláteis, por exemplo, estariam sujeitas a uma avaliação mais subjetiva e a uma maior especulação. Como consequência, suas ações seriam mais afetadas.

Brown e Cliff (2005) relacionam o sentimento à ideia de otimismo: se o otimismo excessivo faz com que os preços sejam superiores aos valores fundamentais, períodos de alto sentimento seriam seguidos por baixos retornos subsequentes, à medida que os preços regressam aos valores intrínsecos. Os autores afirmam ainda que, embora o sentimento tenha baixo poder preditivo no curto prazo, seus efeitos podem perdurar, levando a desvios de preços no longo prazo.

Se as flutuações no sentimento dos investidores irracionais forem correlacionadas e capazes de afetar vários ativos ao mesmo tempo, o risco criado por tais flutuações não poderão ser diversificado. Assim, 0 sentimento seria também um componente explicativo do prêmio de risco, devendo ser precificado do mesmo modo que o risco fundamental (Lee, Shleifer \& Thaler, 1991; Shefrin, 2009). Portanto, sua mensuração se torna relevante para a construção de modelos de apreçamento com abordagem comportamental. 
O principal desafio para testar a importância do sentimento consiste no fato de que ele não é diretamente observável. Segundo Yoshinaga (2009), uma forma de medição proposta pelos pesquisadores é a consolidação de um índice de mercado por meio de outras variáveis observáveis. As proxies utilizadas para esse fim podem ser indiretas - medidas de mercado - ou diretas - pesquisas e questionários.

\subsubsection{Medidas de Sentimento do Investidor}

As medidas de sentimento do investidor podem ser segregadas em medidas diretas e indiretas. As medidas diretas de sentimento do investidor, de modo geral, se baseiam em respostas individuais a questões que buscam quantificar a confiança na economia como um todo ou no mercado de ações em particular. Embora seja uma medida explícita do sentimento, a opinião dos investidores está sujeita a vieses, de modo que as respostas podem não corresponder à realidade. Há também os obstáculos comuns a pesquisas, como a amostra selecionada, a quantidade de respondentes e a periodicidade com que os resultados podem ser obtidos (Da, Engelberg \& Gao, 2015; Yoshinaga, 2009).

Dentre as pesquisas mais comuns nos Estados Unidos, tem-se a US Advisors' Sentiment, que consolida opiniões de analistas de investimentos independentes e é divulgada semanalmente pela empresa Investor's Intelligence, e o índice Bearish Sentiment Index (BSI), que mede a proporção de analistas pessimistas quanto aos preços futuros. A Universidade de Yale, sob a supervisão de Robert Shiller, também divulga um índice de confiança baseado em uma série de questionários coletados desde 1989 (Zhang, 2008).

No Brasil, conforme esclarece Bentes (2006), pode-se citar o Índice de Confiança do Consumidor (ICC) da Federação do Comércio do Estado de São Paulo (Fecomercio), o Índice Nacional de Expectativas do Consumidor (INEC) da Confederação Nacional da Indústria (CNI), a Sondagem de Expectativas do Consumidor (SEC) da Fundação Getúlio Vargas (FGV), entre outros. De modo geral, tais índices analisam as expectativas do indivíduo em relação ao consumo e à economia, bem como sua percepção em relação às condições atuais, não sendo focados, portanto, no mercado de ações em particular.

Já as medidas indiretas de sentimento são representadas por dados financeiros que tentam captar as expectativas dos agentes quanto às mudanças de preços, sendo a maior parte delas baseadas em anomalias empíricas (Zhang, 2008). 0 amplo conjunto de proxies de mercado contempladas pela literatura reflete a diversidade de conceitos e conotações atribuídos ao sentimento do investidor. Neste trabalho, são apresentadas algumas dessas medidas: liquidez; prêmio de dividendos; quantidade e retorno médio das ofertas públicas iniciais; percentual de ações nas novas emissões; proporção de altas e baixas; proporção de put-call; closed-end fund discount; e volatilidade implícita nas opções.

A liquidez das ações é relacionada ao sentimento em diversos estudos, nos quais se sugere que, em mercados onde há restrições à venda a descoberto ou custos de transação, a elevação do sentimento é acompanhada de um aumento do volume de negociações (Baker \& Stein, 2004; Liu, 2015). Pressupõe-se que investidores irracionais adicionarão liquidez ao mercado quando estiverem otimistas, gerando uma sobrevalorização das ações. De acordo com Yoshinaga (2009), uma forma comum de retratar a liquidez é dada pela proporção de ações negociadas em um período e o total médio de ações listadas neste mesmo intervalo.

0 prêmio de dividendos baseia-se no fato de que "empresas que são caracterizadas como boas pagadoras de dividendos são vistas pelos investidores como estáveis" (Yoshinaga, 2009, p. 46). Quando a propensão à especulação está alta, a avaliação de empresas não pagadoras torna-se mais subjetiva e seus retornos mostram-se mais sensíveis ao sentimento. Além disso, os gestores parecem seguir a demanda do mercado, distribuindo dividendos quando as ações de empresas pagadoras estão valorizadas, e retendo dividendos quando os investidores mostram preferência pelas empresas não pagadoras (Baker \& Wurgler, 2004, 2007). 


\section{Bruna Thaísa Braga Nogueira, Bruna Camargos Avelino, Ana Carolina Vasconcelos Colares \& Daniel Eustáquio Assis dos Reis.}

A oferta pública inicial ou initial public offering (IPO) refere-se à primeira venda de ações de uma empresa no mercado. Os IPOs tendem a apresentar altos retornos no dia da emissão - ou seja, preços acima do valor fundamental - e, consequentemente, baixos retornos no longo prazo (Ritter \& Welch, 2002). Para Bank e Brustbauer (2014), é difícil explicar tal padrão sem considerar a influência do sentimento do investidor. Assim, em momentos de entusiasmo, os retornos iniciais são tidos como uma proxy para o sentimento. De forma semelhante, o volume de IPOs de um período refere-se à hipótese de que as empresas se aproveitam do alto sentimento do mercado para emitir novas ações (Zhang, 2008).

Analogamente, o percentual de ações nas novas emissões está relacionado ao aproveitamento do aquecimento do mercado por parte das empresas, que emitiriam ações em momentos de otimismo sob a expectativa de que haja uma sobrevalorização dos títulos (Baker \& Stein, 2004). A variável abrange todas as emissões de ações (não apenas IPOs) em relação ao total de emissões de ações e de títulos de dívida de longo prazo. Conforme Baker e Wurgler (2006), a emissão de ações é seguida de baixos retornos subsequentes.

A proporção de baixas e altas é dada pelo Trading Index ou Indicador Arms, criado por Richard Arms na década de 1970. A medida "pode ser interpretada como a razão entre o volume médio de ações em baixa e o volume médio de ações em alta" (Yoshinaga, 2009, p. 50). Se o índice for maior que um, haverá mais transações de ações em queda do que em alta, indicando um mercado pessimista.

Já a proporção de put-call refere-se às negociações de opções no mercado. 0 índice, conhecido como PCR (do inglês put-call ratio), é dado pela razão entre o volume de opções de venda e de opções de compra transacionadas em determinada data. Quando o mercado está pessimista, os participantes tendem a comprar opções de venda para proteger suas posições correntes ou especular um momento de baixa (Wang. Keswani \& Taylor, 2006). Entretanto, conforme ressaltado por Yoshinaga (2009), características do mercado brasileiro (baixa liquidez de opções de venda e variedade limitada de opções de compra) restringem a utilização do PCR como variável.

O closed-end fund discount (CEFD) refere-se à já citada anomalia dos fundos de investimento fechados. Assume-se que investidores não racionais têm maior propensão a adquirir as cotas de tais fundos, de modo que a diferença entre os preços das ações das cotas e os valores líquidos dos ativos (prêmio ou desconto) seja uma proxy para o sentimento (Lee, Shleifer \& Thaler, 1991). Em momentos de otimismo, por exemplo, os preços das cotas estariam acima do valor fundamental, resultando em um prêmio, ou em um menor desconto.

Por fim, a medida de volatilidade implícita nas opções baseia-se no fato de que os preços das opções aumentam quando a volatilidade esperada do preço do ativo-objeto cresce (Baker \& Wurgler, 2007). 0 índice Market Volatility Index (VIX) é comumente utilizado em estudos sobre o mercado norte-americano (Bandopadhyaya \& Jones, 2008; Da, Engelberg \& Gao, 2015), sendo conhecido também como uma medida de medo do investidor. Quando o VIX está alto - isto é, alta volatilidade implícita -, acredita-se que o sentimento do mercado está baixo e que os investidores estão avessos ao risco.

Segundo Bank e Brustbauer (2014), é importante ressaltar que o sentimento é somente uma das possíveis explicações para as anomalias documentadas no mercado financeiro. Algumas proxies de mercado podem sofrer influência de outros fatores, captando um efeito apenas parcialmente relacionado ao sentimento (Zhang, 2008). A interpretação das relações entre as variáveis, portanto, exige cautela.

\subsection{Estudos Anteriores}

Devido à visibilidade crescente da área de finanças comportamentais, estudos acerca do sentimento do investidor têm se tornado cada vez mais frequentes. Alguns desses trabalhos, assim como seus objetivos e principais resultados, estão sumarizados na Figura 1. 
Figura 1: Estudos sobre o sentimento do investidor.

\begin{tabular}{|c|c|c|}
\hline Autores & Objetivo & Resultados \\
\hline $\begin{array}{l}\text { Lee, Shleifer e } \\
\text { Thaler (1991) }\end{array}$ & $\begin{array}{l}\text { Examinar as mudanças no CEFD à luz da } \\
\text { teoria comportamental. }\end{array}$ & $\begin{array}{l}\text { Há relação negativa entre os retornos das ações e } \\
\text { as mudanças no CEFD, especialmente em } \\
\text { empresas pequenas. }\end{array}$ \\
\hline Brown e Cliff (2005) & $\begin{array}{l}\text { Verificar a relação entre otimismo excessivo } \\
\text { (mensurado por meio de questionário), } \\
\text { supervalorização das ações e baixos } \\
\text { retornos no longo prazo. }\end{array}$ & $\begin{array}{l}\text { Há relação positiva entre a medida de otimismo e a } \\
\text { supervalorização, bem como relação negativa } \\
\text { entre otimismo e retornos no longo prazo ( } 1 \text { a } 3 \\
\text { anos). }\end{array}$ \\
\hline $\begin{array}{l}\text { Baker e Wurgler } \\
\qquad(2006)\end{array}$ & $\begin{array}{l}\text { Investigar se } 0 \text { sentimento afeta } \\
\text { acentuadamente ações de empresas cuja } \\
\text { avaliação é mais subjetiva. }\end{array}$ & $\begin{array}{l}\text { Relação negativa entre sentimento e retornos de } \\
\text { ações de empresas tidas como mais arriscadas. }\end{array}$ \\
\hline Ali, Gurun (2009) & $\begin{array}{l}\text { Examinar a relação entre o sentimento e os } \\
\text { accruals. }\end{array}$ & $\begin{array}{l}\text { Relação positiva entre erro de precificação por } \\
\text { unidade de accruals e períodos de alto nível de } \\
\text { sentimento. }\end{array}$ \\
\hline Yoshinaga (2009) & $\begin{array}{l}\text { Mensurar o sentimento e adicioná-lo como } \\
\text { variável explicativa de um modelo de } \\
\text { precificação de ativos. }\end{array}$ & $\begin{array}{l}\text { Relação negativa entre sentimento e retornos, } \\
\text { indicando um padrão de reversão. }\end{array}$ \\
\hline $\begin{array}{l}\text { Stambaugh, Yu e } \\
\text { Yuan (2012) }\end{array}$ & $\begin{array}{l}\text { Analisar o efeito do sentimento sobre os } \\
\text { retornos, combinado a anomalias de } \\
\text { mercado. }\end{array}$ & $\begin{array}{l}\text { Relação positiva entre alto nível de sentimento e } \\
\text { retornos obtidos por estratégias que exploram } \\
\text { anomalias. }\end{array}$ \\
\hline $\begin{array}{l}\text { Hilliard, } \\
\text { Narayanasamy e } \\
\text { Zhang }(2016)\end{array}$ & $\begin{array}{l}\text { Adicionar o sentimento como variável } \\
\text { explicativa de um modelo de precificação de } \\
\text { ativos. }\end{array}$ & $\begin{array}{l}\text { Aumento do poder explicativo do modelo após a } \\
\text { adição do fator sentimento. }\end{array}$ \\
\hline
\end{tabular}

Fonte: Elaborado pelos autores.

\section{Procedimentos Metodológicos}

Neste trabalho, foram identificados e analisados os fatores relacionados ao sentimento do investidor no mercado brasileiro. Assim, o estudo caracteriza-se, quanto aos fins, como descritivo. Quanto aos meios, trata-se de uma pesquisa documental, tendo em vista que foram utilizados dados provenientes de negociações observadas no mercado de ações brasileiro e dados oriundos das demonstrações contábeis das empresas analisadas. Em relação à abordagem do problema, o estudo caracteriza-se primordialmente como quantitativo, dada a utilização de técnicas de análises de dados e de análises quantitativas focadas na mensuração dos fenômenos.

\subsection{Delimitação da Amostra de Pesquisa}

A população de interesse deste estudo é composta por todas as empresas com ações regularmente negociadas na Brasil, Bolsa, Balcão - B3, no período de 01 de janeiro de 2008 a 31 de dezembro de 2017. A escolha do período inicial justifica-se pela adoção das normas internacionais de contabilidade, comumente conhecidas como International Financial Reporting Standards (IFRS), a partir da promulgação da Lei 11.638, de 28 de dezembro de 2007, ou seja, buscou-se analisar entidades que estivessem sob um mesmo padrão normativo por serem utilizadas, além de variáveis de mercado, variáveis advindas de demonstrações 


\section{Bruna Thaísa Braga Nogueira, Bruna Camargos Avelino, Ana Carolina Vasconcelos Colares \& Daniel \\ Eustáquio Assis dos Reis.}

financeiras. Para atender satisfatoriamente os objetivos da pesquisa, foram excluídas da amostra as empresas que não apresentaram pelo menos um ano de cotações disponíveis. Ademais, por uma decisão metodológica dos autores, não foram contempladas as instituições financeiras, em razão das regras particulares aplicadas às demonstrações contábeis do setor, o que poderia afetar a padronização das variáveis que englobam elementos contábeis.

Se a empresa apresentou mais de uma classe de ações negociada na B3, selecionou-se aquela que apresentou maior negociação no último mês disponível. Essa exigência justifica-se pela utilização de dados contábeis, de modo que estes são os mesmos para ações diferentes. Além disso, como a falta de frequência de preços dificulta a determinação do preço adequado, as empresas deveriam exibir um índice de liquidez em

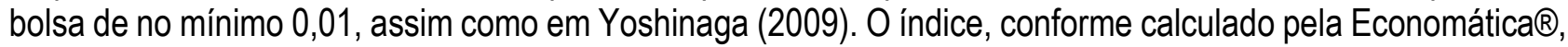
é dado por:

$$
L I Q_{i, t}=100 \frac{d_{i, t}}{D_{t}} \sqrt{\frac{n_{i, t}}{N_{t}} x \frac{v_{i, t}}{V_{t}}}
$$

Em que:

$d_{i, t}$ é o número de dias em que houve pelo menos um negócio com a ação da empresa $i$ no período $t ; D_{t}$ é o número total de dias em que houve negociação na bolsa no período $t ; n_{i, t}$ é a quantidade de negócios com a ação da empresa $i$ no período $t ; N_{t}$ é a quantidade total de negócios de todas as ações no período $t$; $v_{i, t}$ é o volume financeiro dos negócios com a ação da empresa $i$ no período $t$; $V_{t}$ é o volume financeiro total dos negócios de todas as ações no período $t$.

Realizadas as exclusões das companhias que não atendiam aos requisitos citados, foram analisadas 150 empresas. Os dados levantados para calcular o índice foram coletados por meio da base de dados Economática®, com periodicidade mensal, salvo menção contrária.

\subsection{Definição das variáveis}

As variáveis operacionais utilizadas neste trabalho foram empregadas em estudos anteriores, como Baker e Wurgler (2006, 2007) e Yoshinaga (2009), este último utilizado como base para esta pesquisa, e estão descritas a seguir. Tais variáveis são consideradas proxies para o sentimento do investidor.

Percentual de ações nas novas emissões: esta medida é dada por:

$$
S_{t}=\frac{A_{t}}{A_{t}+D E B_{t}}
$$

em que $A_{t}$ é o volume financeiro total emitido através da oferta de ações, e $D E B_{t}$ é o volume financeiro total emitido através da oferta de debêntures.

Quantidade de IPOs: a quantidade de ofertas públicas iniciais, $N I P O_{t}$, foi totalizada a cada mês.

Turnover das ações: o índice turnover, $T U R N_{t}$, foi calculado conforme a seguinte equação: 


$$
T U R N_{t}=\frac{n_{t}}{N_{t}}
$$

em que $n_{t}$ é o somatório das quantidades de títulos negociados no mês em questão e $N_{t}$ é o total médio de ações em circulação em cada mês $t$.

Prêmio de dividendos: para apurar a diferença entre o prêmio de empresas pagadoras e não pagadoras de dividendos, foi utilizada a variável $D I V_{t}$, dada por:

$$
D I V_{t}=\left(\frac{A T_{D, t}-P L_{D, t}+V M_{D, t}}{A T_{D, t}}\right)-\left(\frac{A T_{N D, t}-P L_{N D, t}+V M_{N D, t}}{A T_{N D, t}}\right)
$$

Em que $D$ e $N D$ são utilizados para caracterizar as empresas pagadoras e não pagadoras de dividendos, respectivamente; $A T$ é o ativo contábil total da empresa; $P L$ é o patrimônio líquido e $V M$ é o valor de mercado (preço de fechamento da ação multiplicado pela quantidade de ações). Esta variável foi calculada anualmente, pois os pagamentos de dividendos são informados nos demonstrativos anuais das empresas. Companhias que apresentaram saídas de caixa destinadas à distribuição de dividendos, informadas na Demonstração de Fluxos de Caixa, foram consideradas pagadoras.

Proporção de baixas e altas: esta medida é dada pelo Indicador Arms ou Trading Index, TRIN $N_{t}$, conforme a seguinte equação:

$$
\operatorname{TRIN}_{t}=\frac{V_{B, t}}{Q_{B, t}} \div \frac{V_{A, t}}{Q_{A, t}}
$$

em que $Q_{B, t}$ e $Q_{A, t}$ são a quantidade de ações em baixa e em alta, respectivamente, na data $t$; e $V_{B, t}$ e $V_{A, t}$ são o volume financeiro de ações em baixa e em alta, respectivamente, na data $t$.

\subsection{Técnicas de Análise dos Dados}

A operacionalização deste trabalho deu-se em duas etapas: (i) construiu-se um índice de sentimento do investidor por meio da Análise de Componentes Principais; e (ii) verificou-se a correlação entre 0 índice de sentimento do investidor e o Índice Bovespa (Ibovespa). Os dados foram analisados por meio do software STATA®.

\subsubsection{Análise de Componentes Principais e Análise de correlação}

Baker e Wurgler (2006) ressaltam que cada proxy possivelmente carregará outros componentes não relacionados ao sentimento do investidor, sendo necessário, portanto, obter 0 componente comum que 0 represente. Para tanto, foi empregada a Análise de Componentes Principais (ACP), que consiste em uma técnica estatística não paramétrica multivariada utilizada para reduzir a dimensão de um conjunto de dados. 


\section{Bruna Thaísa Braga Nogueira, Bruna Camargos Avelino, Ana Carolina Vasconcelos Colares \& Daniel Eustáquio Assis dos Reis.}

A ideia central da técnica se baseia em explicar a estrutura da matriz de variâncias e covariâncias de $p$ variáveis originais $(x 1, x 2, \ldots, x p)$ através do cálculo de novas variáveis $(y 1, y 2, \ldots, y p)$, chamadas de componentes principais, que são combinações lineares das variáveis originais (Mingoti, 2005). Para um conjunto de $p$ variáveis originais, é possível a extração de $p$ componentes principais não correlacionadas. Porém, de forma geral, deseja-se explicar o comportamento das $p$ variáveis originais através de um número menor $k(k<p)$ de variáveis, tornando mais simples a interpretação da estrutura dos dados. Neste trabalho, as variáveis originais $(x 1, x 2, \ldots, x p)$ foram representadas pelas cinco proxies já citadas.

As componentes principais são calculadas de tal forma que a primeira componente principal y1 explique o máximo da variância total, ou seja, é sempre a mais representativa, e a p-ésima componente tenha a menor representatividade (Bartholomew, Steele \& Moustaki, 2008). De forma geral, a primeira componente principal pode ser interpretada como o melhor resumo unidimensional da relação entre todas as $p$ variáveis originais. Vale notar, ainda, que a variância total de todas as $p$ componentes principais é igual à variância total das variáveis originais.

Lattin, Carroll e Green (2011) ressaltam que a ACP pode ser sensível às diferenças de escala entre as variáveis. Deste modo, deve-se proceder à padronização das variáveis ou à utilização da matriz de correlações, em substituição à matriz de covariâncias, para extrair as componentes principais. Os autores descrevem ainda diferentes métodos para a escolha das componentes a serem retidas na análise, sendo um deles a proporção da variância explicada. Assim, são descartadas as componentes que explicam apenas uma pequena parcela da variabilidade dos dados. Este critério, porém, poderá variar de acordo com as particularidades dos dados estudados. Outro método de escolha das componentes é a chamada regra de Kaiser (1960), que recomenda a retenção das componentes com autovalores maiores que 1. No entanto, para autovalores próximos à unidade, o pesquisador pode justificar o estabelecimento de um limite um pouco superior ou um pouco inferior a 1. Nesse sentido, "a regra de Kaiser deve ser encarada como uma orientação, não como uma lei inviolável" (Lattin, Carroll \& Green, 2011, p. 92).

Além da ACP, a correlação foi outra técnica utilizada nesta pesquisa. 0 conceito de correlação é utilizado para observar a existência de alguma relação estatisticamente significativa entre duas variáveis (Triola, 2011). Neste estudo, uma vez construído o índice de sentimento do investidor, pretendeu-se verificar se este índice está correlacionado aos preços das ações negociadas no mercado brasileiro. Para esta última variável, utilizou-se como proxy o Ibovespa, que, segundo a B3 (2015), é um indicador de desempenho médio dos ativos mais negociados e representativos do mercado acionário no Brasil. Espera-se que o sentimento esteja positivamente correlacionado ao lbovespa.

0 grau de associação entre duas variáveis $x$ e $y$ é medido pelo coeficiente de correlação $(r)$, que varia entre -1 e 1 (Bussab \& Morettin, 2004). Se $x$ e $y$ têm uma correlação positiva (negativa) forte, $r$ está próximo de 1 (-1). Os métodos mais comumente utilizados são a correlação de Pearson, que avalia a correlação linear entre duas variáveis contínuas, e de Spearman, que avalia a correlação monotônica entre duas variáveis contínuas ou ordinais. Ressalta-se, ainda, que correlação não implica relação de causa e efeito. Neste estudo, utilizou-se a correlação não paramétrica por meio do Coeficiente de Spearman.

\subsection{Temporalidade e Sinal Esperado das variáveis}

Ao construir um índice de sentimento do investidor, é necessário atentar-se à temporalidade das variáveis, uma vez que algumas delas podem apresentar reflexos no sentimento antes de outras. Nesse caso, faz-se necessário defasar as variáveis cujos efeitos não são observados contemporaneamente. Segundo Yoshinaga (2009), espera-se que variáveis relacionadas ao comportamento do investidor sejam defasadas, isto é, antecipem o sentimento do mercado, e que variáveis relacionadas ao comportamento das empresas sejam contemporâneas. Assim, tem-se: $T U R N_{t-1}, D I V_{t-1}, T R I N_{t-1}, N I P O_{t}$ e $S_{t}$.

Em relação ao sinal das variáveis, espera-se que $T U R N$, por representar uma maior negociação na bolsa, bem como NIPO e $S$, por estarem associadas a uma maior oferta de ações por parte das empresas, 
apresentem sinal positivo. Já a variável $D I V$ deve apresentar relação negativa com o sentimento, pois, em tese, empresas pagadoras de dividendos simbolizam investimentos mais seguros e, portanto, mais demandados em períodos de incerteza. Espera-se um sinal negativo também em TRIN, visto que o índice é tido como um indicador de pessimismo.

\section{Análise dos Dados}

\subsection{Estatística Descritivas}

$\mathrm{Na}$ Tabela 1, apresenta-se as principais estatísticas descritivas das variáveis utilizadas na construção do índice de sentimento do investidor: $S, N I P O, T U R N, D I V$ e TRIN.

Tabela 1: Estatísticas descritivas das variáveis que compõem o índice de sentimento

\begin{tabular}{c|c|c|c|c|c|c|c}
\hline Variável & Média & $\begin{array}{c}\text { Desvio } \\
\text { Padrão }\end{array}$ & Mínimo & $1^{0}$ quartil & Mediana & $3^{\circ}$ quartil & Máximo \\
\hline$S$ & 0,3167 & 0,3931 & 0,0000 & 0,0000 & 0,1221 & 0,6930 & 1,0000 \\
\hline$N I P O$ & 0,4667 & 0,9069 & 0,0000 & 0,0000 & 0,0000 & 1,000 & 4,000 \\
\hline$T U R N$ & 0,0497 & 0,0292 & 0,0010 & 0,0114 & 0,0574 & 0,0690 & 0,1026 \\
\hline$D I V$ & 0,2001 & 0,9337 & $-1,6063$ & $-0,4515$ & 0,5941 & 0,9154 & 1,2047 \\
\hline$T R I N$ & 1,0246 & 0,3467 & 0,4572 & 0,7778 & 0,9624 & 1,2129 & 2,6839 \\
\hline
\end{tabular}

Legenda: $S=$ Percentual de ações nas novas emissões, $N I P O=$ Número de IPOs, $T U R N=$ Liquidez dada pelo turnover, $D I V=$ Prêmio de dividendos e TRIN = Proporção de ações em baixa e em alta.

Fonte: Elaborada pelos autores, com base em dados extraídos do STATA®.

As estatísticas descritivas das variáveis $S$ e NIPO evidenciam a estrutura do mercado acionário brasileiro. Em 50\% das observações, o percentual da emissão de ações em relação ao total de emissões (ações e dívidas) no mercado foi inferior a 12,21\%, sugerindo que, na maior parte do tempo, as empresas financiamse primordialmente por capital de terceiros. Além disso, o número máximo de IPOs em um mesmo mês, no período analisado, foi quatro. Comparativamente, Barker e Wurgler (2007), em um estudo sobre o mercado norte-americano, observaram mais de 100 IPOs em determinados meses. Já Yoshinaga (2009), ao analisar empresas com ações regularmente negociadas na B3 no período de 01 de janeiro de 1999 a 31 de dezembro de 2008, encontrou um número máximo de 20 IPOs, sendo a variável totalizada a cada trimestre.

Quanto à variável TURN, observa-se que a quantidade de ações negociadas possui baixa representatividade em relação à quantidade total média de ações listadas no mesmo período. A média do turnover foi de $4,97 \%$ e o valor máximo foi de $10,26 \%$. No trabalho de Yoshinaga (2009), a média desta mesma variável foi de $18,9 \%$ e o valor máximo de $42,3 \%$, lembrando que foram analisados uma amostra e um período distintos.

Constata-se também que, em mais de $50 \%$ das observações, as empresas pagadoras de dividendos apresentaram um prêmio em relação às empresas não pagadoras, visto que a mediana da variável $D I V$ é positiva, situação similar à encontrada no estudo de Yoshinaga (2009). De fato, apenas nos quatro primeiros anos da amostra (2008 a 2011) as empresas não pagadoras foram negociadas com prêmio. Este fato sugere que, a partir de 2012, os investidores mostraram-se mais receosos e, portanto, demandaram um fluxo mais estável de pagamentos. 


\section{Bruna Thaísa Braga Nogueira, Bruna Camargos Avelino, Ana Carolina Vasconcelos Colares \& Daniel Eustáquio Assis dos Reis.}

As estatísticas da variável TRIN indicam que, em média, houve um equilíbrio entre as negociações de ações em baixa e em alta. Além disso, como esperado, o valor mínimo $(0,4572)$ coincide com um momento de alta do Ibovespa, enquanto o valor máximo $(2,6839)$ coincide com um momento de queda.

\subsection{Componentes Principais}

Para determinar a temporalidade correta das variáveis, seguiu-se o procedimento de Baker e Wurgler (2006) e de Yoshinaga (2009): estimou-se um índice de sentimento inicial, $S E N T_{10}$, com as cinco variáveis originais e suas defasagens, permanecendo no modelo as variáveis $(t$ ou $t-1)$ que apresentaram maior correlação com este primeiro índice, conforme exposto na Tabela 2. Assim, foram selecionadas as variáveis $S_{t}, N I P O_{t}, T U R N_{t-1}, D I V_{t}$ e TRIN $N_{t-1}$. Comparativamente, na pesquisa de Yoshinaga (2009), as variáveis selecionadas foram: $S_{t}, N I P O_{t}, T U R N_{t-1}, D I V_{t-1}$ e $T R I N_{t}$, ou seja, as três primeiras coincidiram com as selecionadas neste estudo, enquanto as duas últimas mostraram-se diferentes em termos de temporalidade.

Tabela 2: Correlação entre as variáveis e o índice de sentimento inicial

\begin{tabular}{c|c}
\hline Variável & Correlação com $\boldsymbol{S E N T}_{\mathbf{1 0}}$ \\
\hline$S_{t}$ & $0,658^{* * *}$ \\
\hline$S_{t-1}$ & $0,640^{* * *}$ \\
\hline$N I P O_{t}$ & $0,268^{* * *}$ \\
\hline$N I P O_{t-1}$ & $0,268^{* * *}$ \\
\hline$T U R N_{t}$ & $-0,831^{\star * *}$ \\
\hline$T U R N_{t-1}$ & $-0,839^{\star * *}$ \\
\hline$D I V_{t}$ & $-0,917^{\star * *}$ \\
\hline$D I V_{t-1}$ & $-0,911^{\star * *}$ \\
\hline$T R I N_{t}$ & $0,245^{* * *}$ \\
\hline$T R I N_{t-1}$ & $0,252^{* * *}$ \\
\hline
\end{tabular}

Legenda: $S_{\mathrm{t}}=$ Percentual de ações nas novas emissões; $S_{\mathrm{t}-1}=$ Percentual de ações nas novas emissões (variável defasada); $N I P O_{\mathrm{t}}$ = Número de IPOs; $N I P O_{\mathrm{t}-1}=$ Número de IPOs (variável defasada); $T U R N_{\mathrm{t}}=$ Liquidez dada pelo turnover; $T U R N_{\mathrm{t}-1}=$ Liquidez dada pelo turnover (variável defasada); $D I V_{\mathrm{t}}=$ Prêmio de dividendos; $D I V_{\mathrm{t}-1}=$ Prêmio de dividendos (variável defasada); $T R I N_{\mathrm{t}}=$ Proporção de ações em baixa e em alta; $T R I N_{\mathrm{t}-1}=$ Proporção de ações em baixa e em alta (variável defasada).

Nível de significância: ${ }^{* * *} p<0,01$

Fonte: Elaborada pelos autores, com base em dados extraídos do STATA®.

A única variável a apresentar temporalidade diferente do esperado foi $D I V$, embora a correlação entre $D I V_{t}$ e $S E N T_{10}$ seja próxima à de sua defasagem, $D I V_{t-1}$. Ressalta-se também que todas as correlações são diferentes de zero a um nível de significância de $1 \%$.

Procedeu-se, então, à construção do índice de sentimento por meio da Análise de Componentes Principais. Na Tabela 3, apresenta-se os autovalores e a proporção da variância explicada por cada componente. Observa-se que as duas primeiras componentes possuem autovalor maior que 1 e, segundo a regra de Kaiser, poderiam ser retidas pelo modelo.

Tabela 3: Autovalores e variância explicada pelas componentes principais

\begin{tabular}{c|c|c|c}
\hline Componente & Autovalor & Proporção da variância & Acumulada \\
\hline
\end{tabular}




\begin{tabular}{c|c|c|c}
\hline 1 & 2,2870 & 0,457 & 0,457 \\
\hline 2 & 1,1952 & 0,239 & 0,696 \\
\hline 3 & 0,8433 & 0,169 & 0,865 \\
\hline 4 & 0,4099 & 0,082 & 0,947 \\
\hline 5 & 0,2646 & 0,053 & 1 \\
\hline
\end{tabular}

Fonte: Elaborada pelos autores, com base em dados extraídos do STATA®.

Entretanto, por meio da análise paralela, constata-se que apenas a primeira componente apresenta autovalor maior do que aqueles gerados por simulação randômica, sendo esta, portanto, a única componente mantida no modelo. Observa-se que a primeira componente explica $45,7 \%$ da variância da amostra, refletindo uma parcela significativa da variação comum das variáveis originais. Os autovalores gerados pelo modelo original e pela simulação estão representados na Figura 2.

Figura 2 - Autovalores dos componentes gerados pelo modelo e pela simulação randômica

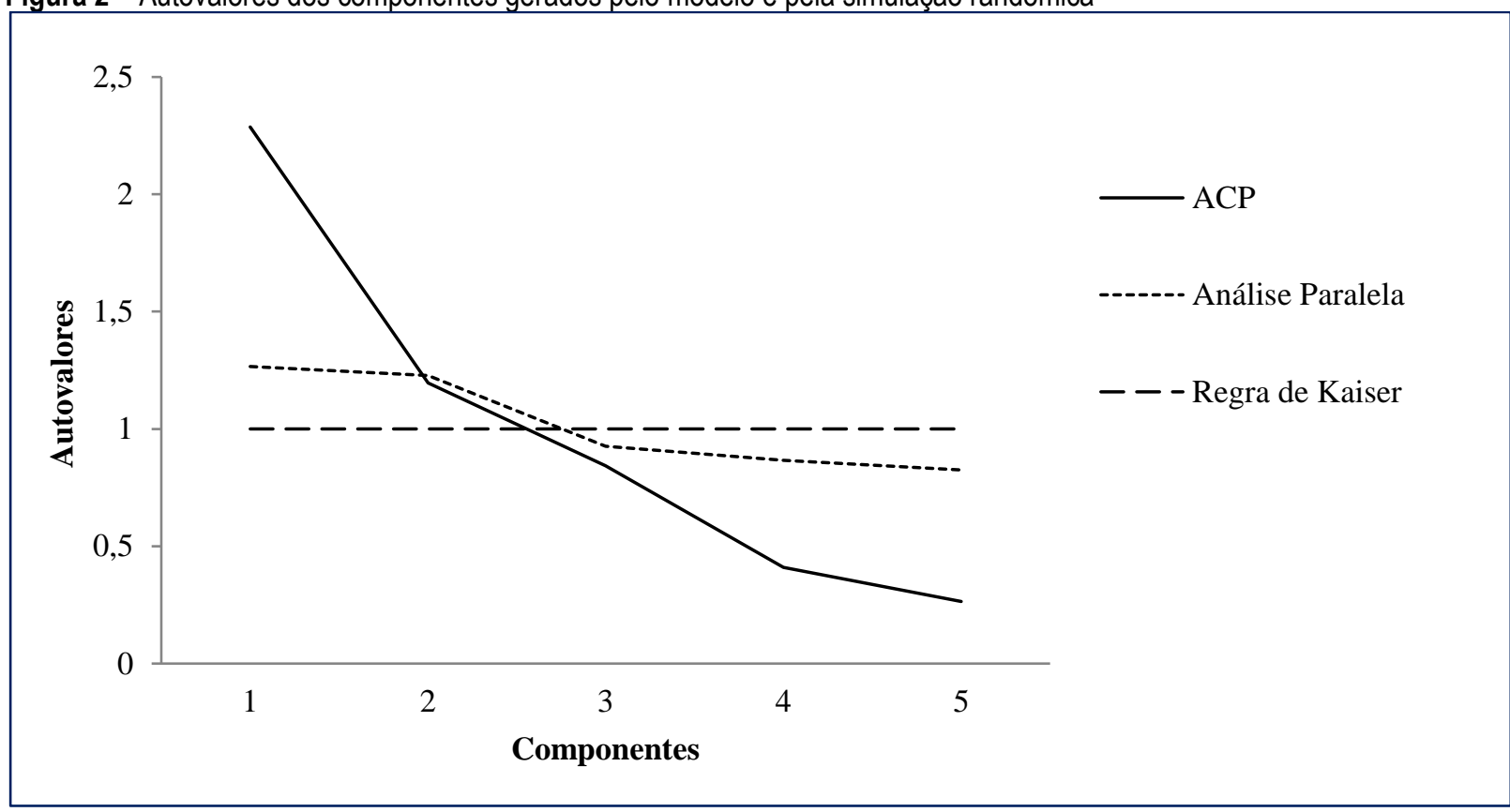

Fonte: Elaborada pelos autores, com base em dados extraídos do STATA®.

Assim, mantendo-se apenas a primeira componente, gerada a partir das cinco variáveis originais, a equação do índice de sentimento é:

$$
\begin{gathered}
\text { SENT }_{t}=0,532 S_{t}+0,335 N I P O_{t}-0,494 T U R N_{t-1} \\
-0,558 D I V_{t}+0,224 T R I N_{t-1}
\end{gathered}
$$

Conforme mencionado por Yoshinaga (2009), espera-se que as variáveis relacionadas a uma maior movimentação do volume de ações estejam diretamente relacionadas ao sentimento do mercado. Assim, S e NIPO, que evidenciam uma maior oferta de ações por parte das empresas, bem como TURN, que representa maior negociação na bolsa e RIPO, que sinaliza um maior incentivo para investimentos em bolsa, deveriam apresentar sinal positivo (Yoshinaga, 2009). Já as variáveis DIV e TRIN, ainda de acordo com Yoshinaga (2009), deveriam apresentar relação negativa com o sentimento, uma vez que se acredita que empresas pagadoras de dividendos têm menos oportunidades de crescimento, e a procura por elas tende a ocorrer de 


\section{Bruna Thaísa Braga Nogueira, Bruna Camargos Avelino, Ana Carolina Vasconcelos Colares \& Daniel Eustáquio Assis dos Reis.}

maneira mais expressiva em épocas em que o mercado está pessimista. De modo contrário, quando o mercado está otimista, a procura deve ser maior por empresas com maiores oportunidades de investimento que, por sua vez, pagam menos dividendos. A variável TRIN, de forma similar, deveria apresentar uma relação inversa com o sentimento, sendo um maior valor um indicativo da perspectiva de um mercado pessimista e vice-versa (Yoshinaga, 2009).

Diante das colocações apresentadas, verifica-se que duas variáveis, $T U R N_{t-1}$ e $T R I N_{t-1}$, apresentaram sinal diferente do esperado, o que pode ter sido motivado pelas crises econômicas que marcaram o período analisado: a crise mundial de 2008, impulsionada pelo colapso do subprime nos Estados Unidos; e a crise brasileira de 2014 a 2016, intervalo marcado pela recessão econômica e pela instabilidade política no país.

De acordo com o Instituto Brasileiro de Geografia e Estatística (IBGE), o crescimento do Produto Interno Bruto (PIB) apresentou uma desaceleração significativa em 2014. Já nos anos de 2015 e 2016, houve um recuo acumulado de $7,2 \%$ no PIB. Além disso, 0 volume de ofertas primárias de ações, debêntures e notas promissórias registradas na Comissão de Valores Mobiliários (CVM) apresentou uma retração de 33\% em 2015, comparativamente a 2014. Neste cenário, os padrões de comportamento dos investidores podem ter sido alterados devido à insegurança e à incerteza presentes no mercado. Assim, em momentos de intenso pessimismo, os agentes podem ter optado por realizar suas perdas e limitar seus prejuízos, o que alteraria a tendência das variáveis de turnover e de proporção de baixas e altas.

$\mathrm{Na}$ Tabela 4, evidencia-se as estatísticas descritivas do índice de sentimento, SENT. Observa-se, por meio da mediana, que o índice é negativo em mais de $50 \%$ das observações.

Tabela 4: Estatísticas descritivas do índice de sentimento

\begin{tabular}{c|c}
\hline Estatística & Valor \\
\hline Média & 0,000 \\
\hline Desvio-padrão & 1,512 \\
\hline Mínimo & $-1,859$ \\
\hline $1^{0}$ quartil & $-1,244$ \\
\hline Mediana & $-0,592$ \\
\hline $3^{0}$ quartil & 1,039 \\
\hline Máximo & 3,638
\end{tabular}

Fonte: Elaborada pelos autores, com base em dados extraídos do STATA®.

Na Figura 3, apresenta-se a evolução do índice de sentimento de 2008 a 2017. 
Figura 3: Evolução do Índice de Sentimento

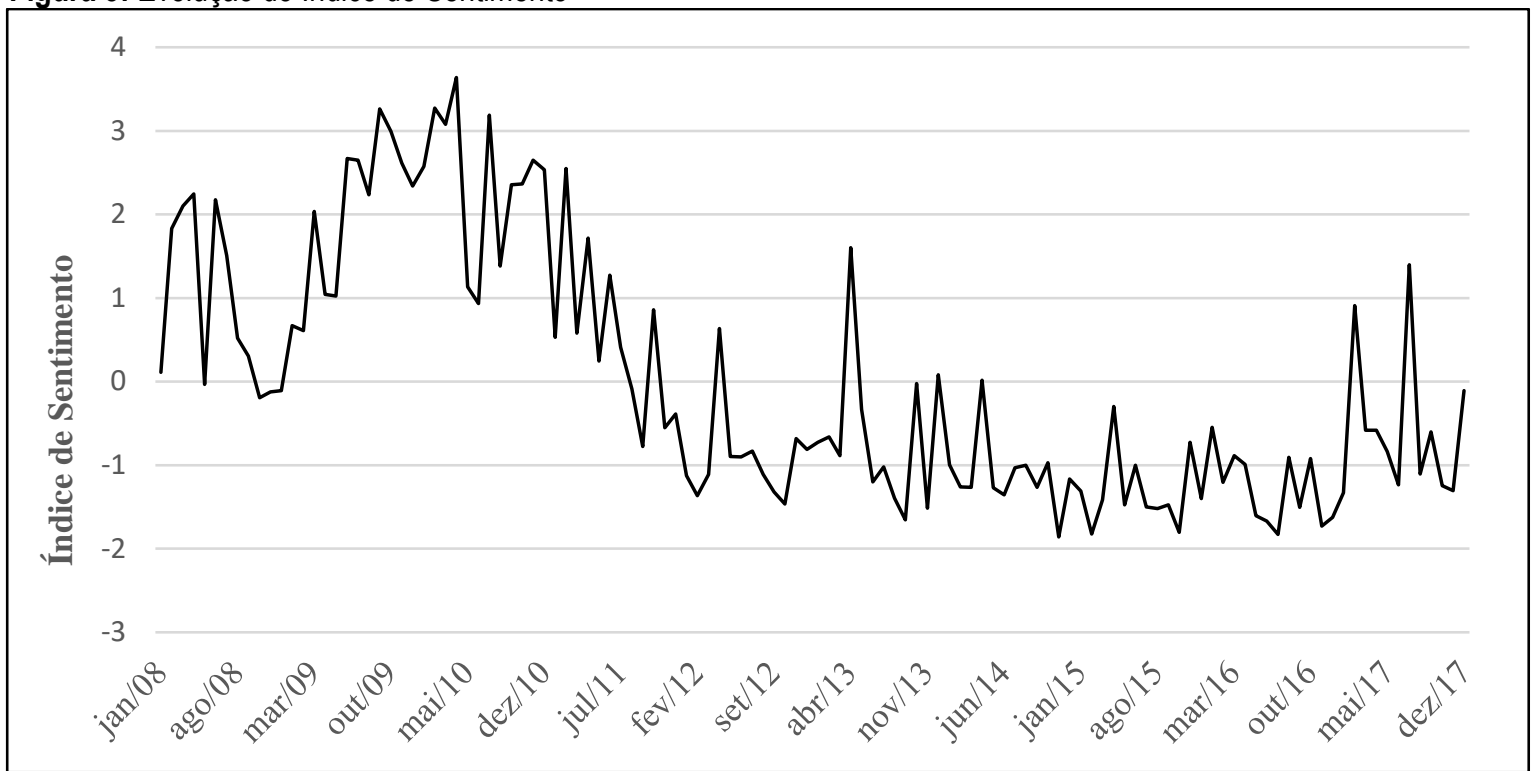

Fonte: Elaborada pelos autores, com base em dados extraídos do STATA®.

A variável SENT apresentou um movimento de queda em 2008, coincidindo com a crise financeira mundial. Nos meses seguintes, houve uma recuperação e o índice alcançou seu pico máximo em abril de 2010. Posteriormente, verificou-se uma nova tendência de queda e, a partir de agosto de 2011, o índice apresentou valores negativos em $91 \%$ dos meses, com eventuais picos positivos. Observa-se que os menores valores foram atingidos entre 2014 e 2016, período de crise econômica no Brasil.

$\mathrm{Na}$ Tabela 5, apresenta-se a matriz de correlações entre SENT e as variáveis que o compõem.

Tabela 5: Matriz de correlação entre SENT e suas variáveis

\begin{tabular}{c|c|c|c|c|c|c}
\hline Variável & $S E N T_{t}$ & $S_{t}$ & $N I P O_{t}$ & $T U R N_{t-1}$ & $D I V_{t}$ & $T R I N_{t-1}$ \\
\hline$S E N T_{t}$ & 1,00 & & & & & \\
\hline$S_{t}$ & $0,805^{* * *}$ & 1,00 & & & & \\
\hline$N I P O_{t}$ & $0,506^{* * *}$ & $0,483^{* * *}$ & 1,00 & & & \\
\hline$T U R N_{t-1}$ & $-0,747^{* *}$ & $-0,386^{* * *}$ & $-0,052$ & 1,00 & & \\
\hline$D I V_{t}$ & $-0,843^{* *}$ & $-0,510^{* * *}$ & $-0,183^{* *}$ & $0,717^{* * *}$ & 1,00 & \\
\hline$T_{R} I N_{t-1}$ & $0,338^{* * *}$ & $0,215^{* *}$ & $0,205^{* *}$ & $-0,056$ & $-0,138^{* *}$ & 1,00 \\
\hline
\end{tabular}

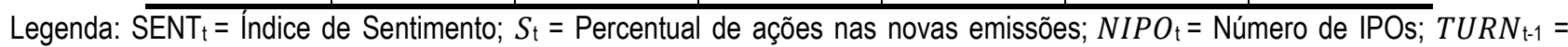
Liquidez dada pelo turnover (variável defasada); $D I V_{\mathrm{t}}=$ Prêmio de dividendos; $T R I N_{\mathrm{t}-1}=$ Proporção de ações em baixa e em alta (variável defasada).

Níveis de significância: ${ }^{* * *} p<0,01,{ }^{* *} p<0,05$,

Fonte: Elaborada pelos autores, com base em dados extraídos do STATA®.

A correlação entre as cinco variáveis originais e $S E N T$ é estatisticamente significativa a $1 \%$. As variáveis com maior correlação são o prêmio de dividendos $\left(D I V_{t}\right)$, o percentual de ações nas novas emissões $\left(S_{t}\right)$ e o turnover defasado $\left(T U R N_{t-1}\right)$.

\section{3 Índice de sentimento e Ibovespa}


Dando continuidade ao estudo, procedeu-se à análise de correlação entre 0 índice de sentimento calculado, $S E N T$, e o lbovespa. Como a variável $S E N T$ não apresentou distribuição normal, utilizou-se a correlação não paramétrica por meio do Coeficiente de Spearman, cujos resultados estão demonstrados na Tabela 6.

Tabela 6: Coeficiente de Correlação

\begin{tabular}{c|c|c}
\hline Variável & SENT & IBOV \\
\hline Índice de Sentimento $(S E N T)$ & 1 & $0,4104^{* * *}$ \\
\hline Ibovespa $(I B O V)$ & $0,4104^{* * *}$ & 1 \\
\hline
\end{tabular}

Nível de significância: ${ }^{* * *} p<0,01$

Fonte: Dados extraídos do STATA®.

As variáveis apresentaram correlação estatisticamente significativa (valor-p: 0,000) de 0,4104, com sinal positivo como esperado. Para a abordagem comportamental, aumentos (diminuições) no nível de sentimento devem ser acompanhados de uma sobrevalorização (desvalorização) das ações, em um primeiro momento, e de uma posterior queda (aumento) nos preços, quando os fundamentos ajustam os valores justos dos títulos. Entretanto, não é possível inferir que as variações no sentimento geraram as variações no lbovespa, uma vez que correlação não implica causalidade.

Ressalta-se que uma correlação perfeita, isto é, no valor de 1, não seria plausível. Os preços das ações são correlacionados a várias variáveis, sendo o sentimento apenas uma delas. Portanto, parte significativa do movimento do Ibovespa não estará correlacionada às mudanças no sentimento dos investidores, e sim a esses outros fatores. Além disso, o lbovespa é composto pelas ações mais representativas em termos de negociação e de liquidez, sendo estas ações normalmente de empresas maiores, mais sólidas e mais transparentes. Esses títulos estão menos sujeitos às mudanças no sentimento e à especulação, pois suas avaliações são mais objetivas.

Desse modo, pretendia-se realizar apenas uma análise geral acerca da relação entre o índice de sentimento do investidor e o lbovespa. Na Figura 4, apresenta-se a evolução dessas duas variáveis no período analisado, transformadas para uma mesma escala. É possível observar que vários picos do índice de sentimento coincidem com momentos de valorização do lbovespa. De modo análogo, quedas no sentimento também se apresentam em sincronia com momentos de desvalorização do lbovespa.

Figura 4: Evolução do Índice de Sentimento e do Ibovespa 


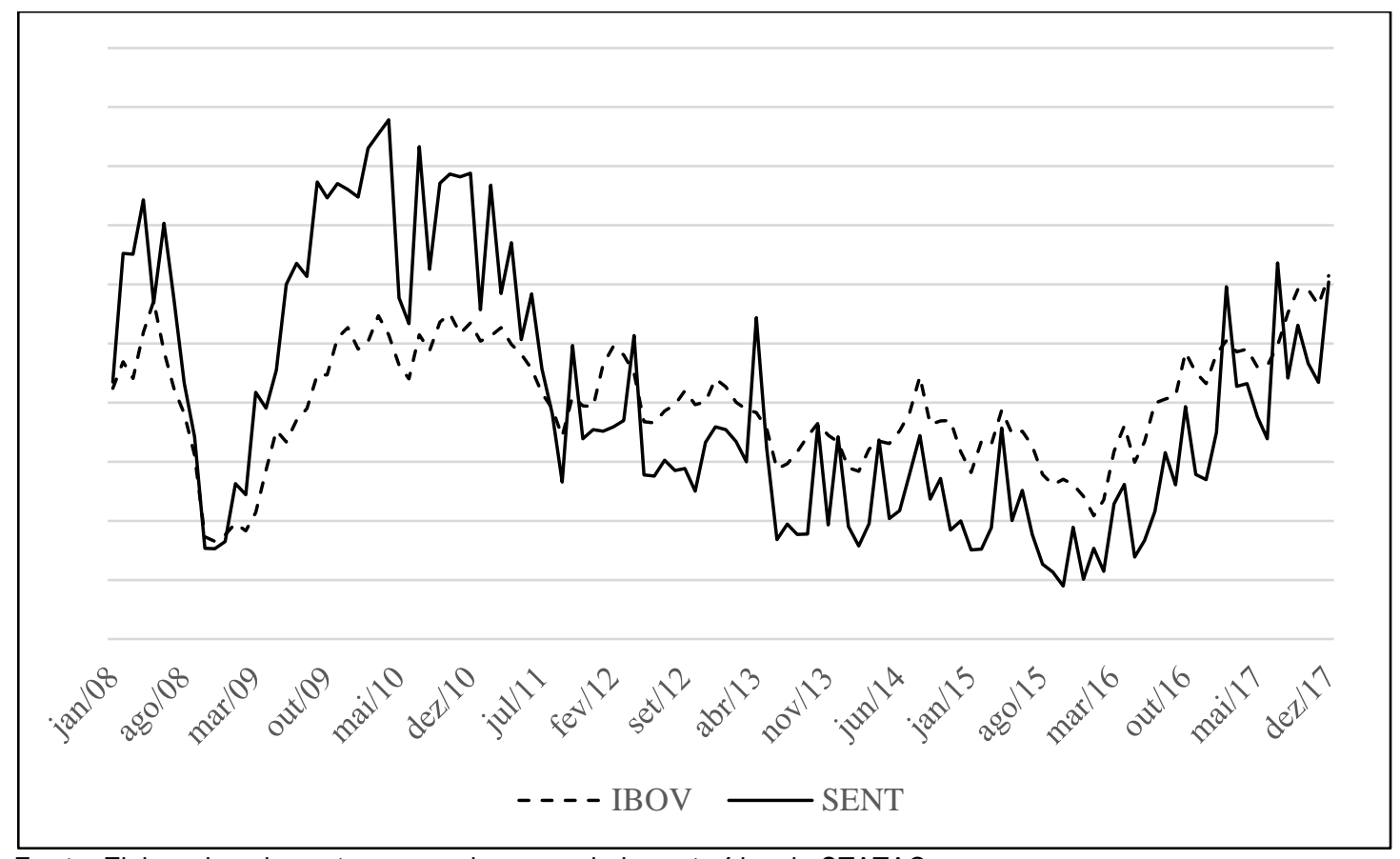

Fonte: Elaborada pelos autores, com base em dados extraídos do STATA®.

Percebe-se que o maior descolamento entre as duas curvas ocorre no período entre 2009 e 2010, durante a recuperação da crise de 2008. Neste período, o índice de sentimento apresenta um aumento mais pronunciado do que o lbovespa, sinalizando uma possível parcela de otimismo e de confiança injustificados. Nos anos seguintes, as discrepâncias entre os dois índices são menores. Observa-se também que, após a crise de 2014-2016, embora o sentimento continue se mostrando volátil, ambas as curvas apresentam uma tendência ascendente. Esse movimento indica a retomada do otimismo e de uma perspectiva positiva por parte dos investidores.

\section{Considerações finais}

Tradicionalmente, as teorias clássicas de finanças modelam o comportamento dos agentes sob a perspectiva da racionalidade e da eficiência informacional. Ainda que os efeitos do sentimento sejam considerados, pressupõe-se que estes são rapidamente eliminados pela atividade dos agentes racionais. Entretanto, nas últimas décadas, estudos têm destacado os efeitos de vieses cognitivos sobre as escolhas dos investidores e apontado padrões no mercado que não são satisfatoriamente explicados pela abordagem clássica (Daniel \& Hirshleifer, 2015).

Esta pesquisa se propôs a construir e a analisar um índice de sentimento dos investidores de um modo agregado, seguindo a metodologia utilizada em Yoshinaga (2009). Considerando que o sentimento é refletido em padrões observáveis no mercado de ações, as variáveis utilizadas para a construção do índice foram: (i) percentual de emissão de ações em relação ao total de emissões de ações e de títulos de dívida; (ii) quantidade de IPOs; (iii) volume de negociações, dado pelo turnover; (iv) prêmio de empresas pagadoras de dividendos e (v) proporção entre o volume negociado de ações em baixa e ações em alta. Por meio da técnica de ACP, capturou-se a variação comum a essas variáveis, gerando o índice de sentimento.

Embora duas variáveis tenham apresentado sinal diferente do esperado, os resultados empíricos do trabalho sugerem que o índice de sentimento captou, ainda que parcialmente, as variações das crenças dos investidores. Observa-se que as principais tendências de queda ou de subida do índice coincidem com momentos de instabilidade ou de prosperidade econômica no Brasil. 


\section{Bruna Thaísa Braga Nogueira, Bruna Camargos Avelino, Ana Carolina Vasconcelos Colares \& Daniel Eustáquio Assis dos Reis.}

Partindo do pressuposto de que o sentimento está correlacionado aos preços das ações, objetivou-se também verificar sua relação com o lbovespa. A correlação positiva entre as duas variáveis $(r=0,4104)$ indica que, de fato, aumentos (diminuições) no nível de sentimento estão parcialmente correlacionados a tendências de subida (queda) no lbovespa, no período de 2008 a 2017. Este resultado, condizente com a teoria comportamental, sugere que o sentimento é, portanto, um fator relevante e consistente no mercado brasileiro.

Algumas limitações deste estudo devem ser consideradas na interpretação dos resultados. Primeiramente, como sugerido por Sibley, Xing e Zhang (2012), é possível que o índice de sentimento construído não seja isento da influência dos ciclos econômicos e contenha fatores de risco baseados em expectativas racionais. Nesse caso, a análise da evolução do sentimento e da correlação dele com o lbovespa seria prejudicada, visto que o índice seria composto não apenas pelo sentimento (crenças não justificadas pelos fundamentos), mas também por um componente racional - relacionado, por exemplo, à taxa básica de juros, à taxa de desemprego, ao Produto Interno Bruto (PIB), entre outros.

Dentre as limitações empíricas, tem-se a delimitação da amostra, o corte do período e a definição das variáveis. A construção do índice para o mercado brasileiro está limitada à disponibilidade de dados, de modo que diversas empresas que não atendiam aos critérios mínimos de negociabilidade em bolsa foram excluídas da amostra. Além disso, o recorte temporal de 2008 a 2017 impede que os resultados sejam extrapolados ou generalizados. Por fim, as análises são restritas às proxies utilizadas pois, ainda que elas tenham sido empregadas em estudos anteriores, não há um consenso acerca da mensuração do sentimento do investidor.

Para estudos futuros, recomenda-se a inclusão de novas proxies, a observação e a possível exclusão do efeito de variáveis do ciclo econômico sobre o sentimento, a ampliação do período de análise e das empresas contempladas, bem como a utilização do índice de sentimento em análises paralelas, principalmente por meio da estimação de modelos de regressão linear múltipla que incluam variáveis que controlem aspectos contábeis, sociais, políticos, geográficos, dentre outros, com o propósito de explorar o seu poder explicativo e preditivo.

\section{Referências}

Ackert, L. F. \& Deaves, R. (2010). Behavioral Finance: Psychology, Decision-Making and Markets. Mason: South-Western Cengage Learning.

Akerlof, G. \& Shiller, R. (2009). Animal Spirits: How Human Psychology Drives the Economy, and Why it Matters for Global Capitalism. 1. ed. Princeton: Princeton University Press.

Ali, A. \& Gurun, U. (2009). Investor sentiment, accruals anomaly, and accruals management. Journal of Accounting, Auditing \& Finance, 24(3), 415-431.

Assaf Neto, A. (2014). Mercado Financeiro. São Paulo: Atlas.

B3. (2015). Metodologia do Índice Bovespa. São Paulo. Recuperado em 31 maio, 2018, de http://www.bmfbovespa.com.br/lumis/portal/file/fileDownload.jsp?fileld=8A828D29514A326701516E695D7F65C0.

Baker, M. \& Stein, J. C. (2004). Market liquidity as a sentiment indicator. Journal of Financial Markets, 7(3), 271-299.

Baker, M. \& Wurgler, J. (2004). A catering theory of dividends. Journal of Finance, 59(3), 1125-1165.

Baker, M. \& Wurgler, J. (2006). Investor sentiment and the cross-section of stock returns. The Journal of Finance, 61(4), 1645-1680.

Baker, M. \& Wurgler, J. (2007). Investor sentiment in the stock market. Journal of Economic Perspectives, 21(2), $129-152$.

Bandopadhyaya, A. \& Jones, A. L. (2008). Measures Of Investor Sentiment: A Comparative Analysis. Journal of Business \& Economics Research, 6(8), 27-34.

Bank, M. \& Brustbauer, J. (2014). Investor Sentiment in Financial Markets. Unpublished Working Paper, 1-24, 2014. Recuperado em 13 agosto, 2017, de http://www.uibk.ac.at/ibf/mitarbeiter/bank/investor-sentiment-in-financial-markets.pdf.

Banz, R. W. (1981). The Relationship between Return and Market Value of Common Stocks. Journal of Financial Economics, 9(1), 318. 
Barberis, N. \& Thaler, R. (2003). A survey of behavioral finance. In: Handbook of the Economic of Finance. New York: Elsevier Science, 1053-1116.

Bartholomew, D. J., Steele, F. \& Moustaki, I. (2008). Analysis of multivariate social science data. 2 ed. CRC Press.

Bentes, F. G. M. (2006). O poder preditivo do Índice de Confiança do Consumidor no Brasil: uma análise através de vetores autoregressivos. 2006. 96 f. Dissertação (Mestrado Profissionalizante em Economia) - Programa de Pós-Graduação e Pesquisa em Administração e Economia da Faculdade IBMEC, São Paulo.

Black, F. (1986). Noise. The Journal of Finance, 41(3), 529-543, 1986.

Brasil. (2007). Lei no 11.638, de 28 de dezembro de 2007. Altera e revoga dispositivos da lei $n^{\circ} 6.404$, de 15 de dezembro de 1976 , e da lei $n^{\circ} 6.385$, de 7 de dezembro de 1976, e estende às sociedades de grande porte disposições relativas à elaboração e divulgação de demonstrações financeiras. Diário Oficial da União, Poder Executivo, Brasília, DF, 28 dez. 2007. Edição Extra, p. 2

Brealey, R. A., Myers, S. C. \& Allen, F. (2013). Princípios de Finanças Corporativas. Porto Alegre: AMGH.

Brown, G. W. \& Cliff, M. T. (2005). Investor Sentiment and Asset Valuation. The Journal of Business, 78(2), 405-440.

Bussab, W. O. \& Morettin, P. A. (2004). Estatística Básica. 5. ed. São Paulo: Saraiva.

Camargos, M. A. \& Barbosa, F. V. (2003). Teoria e evidência da eficiência informacional do mercado de capitais brasileiro. Caderno de Pesquisas em Administração, 10(1), 41-55.

Camerer, C. \& Loewenstein, G. (2004). Behavioral economics: Past, present, future. In: Advances in Behavioral Economics. Princeton: Princeton University Press, 3-51.

Carhart, M. M. (1997). On persistence in mutual fund performance. The Journal of Finance, 52(1), 57-82.

Castro, D. D. (2015). Impacto de operações de venda a descoberto na eficiência de mercado. 2015. 46 f. Dissertação (Mestrado em Ciências) - Faculdade de Economia, Administração e Contabilidade da Universidade de São Paulo, São Paulo.

Cen, L., Hilary, G. \& Wei, K. C. J. (2013). The Role of Anchoring Bias in the Equity Market: Evidence from Analysts' Earnings Forecasts and Stock Returns. Journal of Financial and Quantitative Analysis, 48(1), 47-76.

Chung, S., Hung, C. \& Yeh, C. (2012). When Does Investor Sentiment Predict Stock Returns? Journal of Empirical Finance, 19(2), 217-240.

Comissão de Valores Mobiliários - CVM. (2018). Distribuições Públicas. Recuperado em 15 junho, 2018, de http://www.cvm.gov.br/menu/acesso_informacao/serieshistoricas/serieshistoricas/distribuicoes_publicas.html

Da, Z., Engelberg, J. \& Gao, P. (2015). The sum of all FEARS investor sentiment and asset prices. Review of Financial Studies, 28(1), $1-32$.

Daniel, K. \& Hirshleifer, D. (2015). Overconfident Investors, Predictable Returns, and Excessive Trading. Journal of Economic Perspectives, 29(4), 61-88.

De Bondt, W. \& Thaler, R. (1985). Does the Stock Market Overreact? The Journal of Finance, 40(3), 793-805.

De Bondt, W., Muradoglu, Y. G., Shefrin, H. \& Staikouras, S. K. (2008). Behavioral Finance: Quo Vadis? Journal of Applied Finance, 18(2), 7-21.

De Long, B., Shleifer, A., Summers, L. H. \& Waldmann, R. J. (1990). Noise Trader Risk in Financial Markets. Journal of Political Economy, 98(4), 703-738.

Fama, E. (1965). Random Walk in Stock-Market Prices. Financial Analysts Journal, 55-59.

Fama, E. (1970). Efficient Capital Markets: A Review of Theory and Empirical Work. Journal of Business, 25(2), 383-417.

Fama, E. \& French, K, R. (1992). The Cross-Section of Expected Stock Returns. The Journal of Finance, 47(2), 427-465.

Fama, E. \& French, K, R. (1993). Common Risk Factors in the Returns on Stocks and Bonds. Journal of Financial Economics, 33, 356.

Fama, E. \& French, K, R. (2004). The Capital Asset Pricing Model: Theory and Evidence. Journal of Economic Perspectives, 18(3), 25-46.

Fama, E. \& French, K, R. (2015). A Five-Factor Asset Pricing Model. Journal of Financial Economics, 116(1), 1-22.

Fernandes, C. M. A. (2015). Sentimento e Rendibilidade nos Mercados de Capitais. 2015. 243 f. Universidade de Coimbra, Coimbra

Hilliard, J., Narayanasamy, A. \& Zhang, S. (2016). Market Sentiment as a Factor in Asset Pricing. SSRN Electronic Journal, 1(1), 145. Recuperado em 11 agosto, 2017, de https://papers.ssrn.com/sol3/papers.cfm?abstract_id=2716353. 


\section{Bruna Thaísa Braga Nogueira, Bruna Camargos Avelino, Ana Carolina Vasconcelos Colares \& Daniel Eustáquio Assis dos Reis.}

Hirshleifer, D. \& Shumway, T. (2003). Good Day Sunshine: Stock Returns and the Weather. The Journal of Finance, 58(3), 10091032.

Instituto Brasileiro de Geografia e Estatística - IBGE. (2018). Contas Nacionais Trimestrais. Rio de Janeiro. ecuperado em 15 junho, 2018, de https://ww2.ibge.gov.br/home/estatistica/indicadores/pib/defaultcnt.shtm.

Jegadeesh, N. \& Titman, S. (1993). Returns to Buying Winners and Selling Losers: Implications for Stock Market Efficiency. The Journal of Finance, 48(1), 65-91.

Kahneman, D. \& Tversky, A. (1974). Judgement under Uncertainty: Heuristics and Biases. Science, 185(4157), 1124-1131.

Kahneman, D. \& Tversky, A. (1949). Prospect Theory: An Analysis of Decision under Risk. Econometrica, 47(2), 263-292.

Kaiser, H. F. (1960). The Application of Electronic Computers to Factor Analysis. Educational and Psychological Measurement, 20(1), $141-151$.

Keynes, J. M. (1936). The General Theory of Employment, Interest, and Money. London: Macmillan.

Kim, T. \& Ha, A. (2010). Investor Sentiment and Market Anomalies. SSRN Electronic Journal, November, 2010. Recuperado em 10 agosto, 2017, de http://papers.ssrn.com/sol3/papers.cfm?abstract_id=1663649.

Lattin, J. M., Carroll, J. D. \& Green, P. E. (2011). Análise de Dados Multivariados. 1. ed. São Paulo: Cengage Learning.

Lee, C., Shleifer, A. \& Thaler, R. (1991). Investor sentiment and the closed end fund puzzle. The Journal of Finance, 46(1), 75-109.

Lintner, J. (1965). The Valuation of Risk Assets and the Selection of Risky Investments in Stock Portfolios and Capital Budgets. Review of Economics and Statistics, 47(1), 13-37.

Liu, S. (2015). Investor Sentiment and Stock Market Liquidity. Journal of Behavioral Finance, 16(1), 51-67.

Loewenstein, G. F. (1992). The fall and rise of psychological explanations in the economics of intertemporal choice. In: Choice Over Time. New York: Russel Sage Foundation, 3-34.

Malkiel, B. G. (2003). The Efficient Market Hypothesis and Its Critics. Journal of Economic Perspectives, 17(1), 59-82.

Markowitz, H. (1952). Portfolio Selection. The Journal of Finance, 7(1), 77-91.

Martins, E., Pereira, B. B., Amorim, T. N., Oliveira, V. H. \& Oliveira, E. A. (2010). Índice de Sentimento do Investidor de Baker e Wurgler (2006) e o spread book-to-market dos IPOs no Brasil. Revista de Finanças Aplicadas, 1-11.

Merton, R. C. (1973). An Intertemporal Capital Asset Pricing Model. Econometrica, 41(5), 867-887.

Merton, R. C. (1992).Continuous-Time Finance. Willey-Blackwell.

Mingoti, S. A. (2005). A análise de dados através de métodos de estatística multivariada: uma abordagem aplicada. Belo Horizonte: Editora UFMG.

Mossin, J. (1966). Equilibrium in a Capital Asset Market. Econometrica, 34(4), 768-783.

Read, C. (2012). The Efficient Market Hypothesists: Bachelier, Samuelson, Fama, Ross, Tobin and Shiller. 1. ed. New York: Springer.

Ritter, J. R. \& Welch, I. (2002). A review of IPO activity, pricing, and allocations. Journal of Finance, 57(4), 1795-1828.

Rosenberg, B., Reid, K. \& Lanstein, R. (1985). Persuasive evidence of market inefficiency. The Journal of Portfolio Management, 11(3), p. 9-16.

Ross, S. A. (1976). The arbitrage theory of capital asset pricing. Journal of Economic Theory, 13(3), 341-360.

Rubinstein, M. (2001). Rational Markets: Yes or No? The Affirmative Case. Financial Analysts Journal, 57(3), 15-29.

Santos, J. O., Famá, R.\& Mussa, A. (2012). A adição do fator de risco momento ao modelo de precificação de ativos dos três fatores de Fama \& French aplicado ao mercado acionário brasileiro. REGE-Revista de Gestão, 19(3), 453-471.

Schaul, K. (2013). Investor sentiment: The impact of a search-based measure of sentiment on equity market returns. 2013.55 f. Tilburg University, Tilburg.

Schmeling, M. (2009). Investor sentiment and stock returns: Some international evidence Investor sentiment and stock returns. Journal of Empirical Finance, 16(407), 1-41.

Sharpe, W. F. (1964). Capital Asset Prices: a Theory of Market Equilibrium Under Conditions of Risk. The Journal of Finance, 19(3), 425-442.

Shefrin, H. (2009). Behavioralizing Finance. Foundations and Trends in Finance, 4(1-2), 1-184. 
Shiller, R. (1981). Do Stock Prices Move Too Much to be Justified by Subsequent Changes in Dividends? American Economic Review, $71(3), 421-436$.

Shiller, R. (2003). From Efficient Markets Theory to Behavioral Finance. The Journal of Economic Perspectives, 17(1), 83-104.

Shiller, R. (2000). Irrational Exuberance. 1. ed. Princeton: Princeton University Press.

Shleifer, A. (2000). Inefficient Markets: An Introduction to Behavioral Finance. 1. ed. Oxford: Oxford University Press.

Shleifer, A. \& Summers, L. (1990). The Noise Trader Approach to Finance. Journal of Economic Perspectives, 4(2), 19-33.

Shleifer, A. \& Vishny, R. (1997). The Limits to Arbitrage. The Journal of Finance, 52, 35-55.

Sibley, S. E., Xing, Y. \& Zhang, X. (2012). Is "Sentiment" Sentimental? Social Science Research Network Electronic Jounal, 1-67. Recuperado em 10 agosto, 2017, de http://www.ruf.rice.edu/ yxing/sentiment_v1_20121115.pdf.

Simon, H. (1955). A Behavioral Model of Rational Choice. The Quarterly Journal of Economics, 69(1), 99-118.

Slovic, P. (1972). Psychological Study of Human Judgement: Implications for Investment Decision Making. The Journal of Finance, 27(4), 779-799.

Stambaugh, R. F., Yu, J. \& Yuan, Y. (2012). The short of it: Investor sentiment and anomalies. Journal of Financial Economics, 104(2), 288-302.

Statman, M. (1995). Behavioral Finance versus Standard Finance. AIMR Conference Proceedings, 1995(7), 14-22.

Thaler, R. \& De Bondt, W. F. M. (1985). Does the Stock Market Overreact? The Journal of Finance, 40(3), 793-805.

Thaler, R. (2016). Behavioral economics: Past, present, and future. American Economic Review, 106(7), 1577-1600.

Thaler, R. (1999). The End of Behavioral Finance. Financial Analysts Journal, 55(6), 12-17.

Thaler, R. (2015). Misbehaving: The Making of Behavioral Economics. 1. ed. New York: W. W. Norton \& Company.

Timmermann, A. \& Granger, C. W. J. (2004). Efficient market hypothesis and forecasting. International Journal of Forecasting, 20(1), 15-27.

Treynor, J. (1961). Toward a Theory of Market Value of Risky Assets. Unpublished Manuscript.

Triola, M. F. (2011). Introdução a Estatística. 10. ed. São Paulo: LTC.

Wang, Y. H., Keswani, A. \& Taylor, S. J. (2006). The relationships between sentiment, returns and volatility. International Journal of Forecasting, 22(1), 109-123.

Yoshinaga, C. E. (2009). A relação entre índice de sentimento do mercado e as taxas de retorno das ações: uma análise com dados em painel. 2009. 176 f. Tese (Doutorado em Administração) - Universidade de São Paulo, São Paulo.

Zhang, C. (2008). Defining, Modeling, and Measuring Investor Sentiment. University of California, Berkeley, Department of Economics.

\section{DADOS DOS AUTORES}

\section{Bruna Thaísa Braga Nogueira}

Bacharel em Ciências Contábeis pela Universidade Federal de Minas Gerais (UFMG)

Endereço: Av. Antônio Carlos, 6627, Pampulha,

CEP: 31270-901- Belo Horizonte/MG

Telefone: 5531 3409-7060

E-mail: brunatbnogueira@gmail.com

\section{Bruna Camargos Avelino}

Doutora em Controladoria e Contabilidade pela Universidade de São Paulo (USP)

Professora Adjunta do Departamento de Ciências Contábeis da UFMG

Endereço: Av. Antonio Carlos, 6627, Pampulha,

CEP: 31270-901- Belo Horizonte/MG

Telefone: 5531 3409-7060

E-mail: bcavelino@gmail.com 
Bruna Thaísa Braga Nogueira, Bruna Camargos Avelino, Ana Carolina Vasconcelos Colares \& Daniel Eustáquio Assis dos Reis.

\section{Ana Carolina Vasconcelos Colares}

Doutoranda e Mestre em Ciências Contábeis pela Universidade Federal de Minas Gerais (UFMG)

Professora Assistente do Departamento de Contabilidade da PUC Minas

Endereço: Rua Walter lanni, 255, São Gabriel

CEP: 31980-110 - Belo Horizonte/MG

Telefone: 5531 3409-7060

E-mail: carolina_colares@hotmail.com

\section{Daniel Eustáquio Assis dos Reis}

Bacharel em Ciências Contábeis pela Universidade Federal de Minas Gerais (UFMG)

Auditor-Fiscal da Receita Federal do Brasil

Endereço: Avenida Afonso Pena, 1.316, Centro

CEP: 30130-009 - Belo Horizonte/MG

Telefone: 5531 3218-6520

E-mail: danieleareis1@gmail.com

\section{Contribuição dos Autores:}

\begin{tabular}{|c|c|c|c|c|}
\hline Contribuição & $\begin{array}{c}\text { Bruna Thaísa } \\
\text { Braga } \\
\text { Nogueira }\end{array}$ & $\begin{array}{c}\text { Bruna } \\
\text { Camargos } \\
\text { Avelino }\end{array}$ & $\begin{array}{c}\text { Ana Carolina } \\
\text { Vasconcelos } \\
\text { Colares }\end{array}$ & $\begin{array}{c}\text { Daniel } \\
\text { Eustáquio } \\
\text { Assis dos } \\
\text { Reis }\end{array}$ \\
\hline 1. Concepção do assunto e tema da pesquisa & $\mathrm{X}$ & & & \\
\hline 2. Definição do problema de pesquisa & $x$ & $X$ & & \\
\hline $\begin{array}{l}\text { 3. Desenvolvimento das hipóteses e constructos da } \\
\text { pesquisa (trabalhos teórico-empíricos) }\end{array}$ & $X$ & $X$ & & \\
\hline $\begin{array}{l}\text { 4. Desenvolvimento das proposições teóricas } \\
\text { (trabalhos teóricos os ensaios teóricos) }\end{array}$ & & & & \\
\hline 5. Desenvolvimento da plataforma teórica & $X$ & & & \\
\hline 6. Delineamento dos procedimentos metodológicos & $X$ & $X$ & & \\
\hline 7. Processo de coleta de dados & $X$ & & & \\
\hline 8. Análises estatísticas & $X$ & $X$ & & \\
\hline 9. Análises e interpretações dos dados coletados & $X$ & & $X$ & \\
\hline 10. Considerações finais ou conclusões da pesquisa & $X$ & & & \\
\hline 11. Revisão crítica do manuscrito & & $X$ & $X$ & $X$ \\
\hline 12. Redação do manuscrito & $X$ & $X$ & $X$ & $X$ \\
\hline
\end{tabular}

